\title{
Recent advances in (therapeutic protein) drug development
}

\section{[version 1; peer review: 2 approved]}

\author{
H.A. Daniel Lagassé, Aikaterini Alexaki, Vijaya L. Simhadri, Nobuko H. Katagiri, \\ Wojciech Jankowski, Zuben E. Sauna, Chava Kimchi-Sarfaty
}

Hemostasis Branch, Division of Plasma Protein Therapeutics, Office of Tissues and Advanced Therapies, Center for Biologics Evaluation and Research, U.S. Food and Drug Administration, Silver Spring, MD, USA

V1 First published: 07 Feb 2017, 6(F1000 Faculty Rev):113

https://doi.org/10.12688/f1000research.9970.1

Latest published: 07 Feb 2017, 6(F1000 Faculty Rev):113

https://doi.org/10.12688/f1000research.9970.1

\section{Abstract}

Therapeutic protein drugs are an important class of medicines serving patients most in need of novel therapies. Recently approved recombinant protein therapeutics have been developed to treat a wide variety of clinical indications, including cancers, autoimmunity/inflammation, exposure to infectious agents, and genetic disorders. The latest advances in protein-engineering technologies have allowed drug developers and manufacturers to fine-tune and exploit desirable functional characteristics of proteins of interest while maintaining (and in some cases enhancing) product safety or efficacy or both. In this review, we highlight the emerging trends and approaches in protein drug development by using examples of therapeutic proteins approved by the U.S. Food and Drug Administration over the previous five years (2011-2016, namely January 1, 2011, through August 31, 2016).

\section{Keywords}

therapeutic protein drugs, protein therapeutics, cancer therapeutics, biosimilar, recombinant DNA-derived therapeutic proteins

\section{Open Peer Review}

Approval Status

1 2

version 1

07 Feb 2017

Faculty Reviews are review articles written by the prestigious Members of Faculty Opinions. The articles are commissioned and peer reviewed before publication to ensure that the final, published version is comprehensive and accessible. The reviewers who approved the final version are listed with their names and affiliations.

1. Janice Reichert, The Antibody Society,

Framingham, USA

2. Yusuf Tutar, Cumhuriyet University, Sivas,

Turkey

Any comments on the article can be found at the end of the article. 
Corresponding authors: Zuben E. Sauna (Zuben.Sauna@fda.hhs.gov), Chava Kimchi-Sarfaty (Chava.kimchi-sarfaty@fda.hhs.gov)

Competing interests: The authors declare that they have no competing interests.

Grant information: The author(s) declared that no grants were involved in supporting this work.

Copyright: @ 2017 Lagassé HAD et al. This is an open access article distributed under the terms of the Creative Commons Attribution License, which permits unrestricted use, distribution, and reproduction in any medium, provided the original work is properly cited.

How to cite this article: Lagassé HAD, Alexaki A, Simhadri VL et al. Recent advances in (therapeutic protein) drug development [version 1; peer review: 2 approved] F1000Research 2017, 6(F1000 Faculty Rev):113 https://doi.org/10.12688/f1000research.9970.1

First published: 07 Feb 2017, 6(F1000 Faculty Rev):113 https://doi.org/10.12688/f1000research.9970.1 


\section{Protein engineering}

The manufacturing and production of therapeutic proteins are highly complex processes ${ }^{1-3}$. For example, a typical protein drug may include in excess of 5,000 critical process steps, many times greater than the number required for manufacturing a small-molecule $\operatorname{drug}^{4}$ (Figure 1a).

Similarly, protein therapeutics, which include monoclonal antibodies as well as large or fusion proteins, can be orders-of-magnitude larger in size than small-molecule drugs, having molecular weights exceeding $100 \mathrm{kDa}$ (Figure 1b). In addition, protein therapeutics exhibit complex secondary and tertiary structures that must be maintained. Protein therapeutics cannot be completely synthesized by chemical processes and have to be manufactured in living cells or organisms; consequently, the choices of the cell line, species origin, and culture conditions all affect the final product characteristics ${ }^{5-7}$. Moreover, most biologically active proteins require posttranslational modifications that can be compromised when heterologous expression systems are used. Additionally, as the products are synthesized by cells or organisms, complex purification processes are involved. Furthermore, viral clearance processes such as removal of virus particles by using filters or resins, as well as inactivation steps by using low $\mathrm{pH}$ or detergents, are implemented to prevent the serious safety issue of viral contamination of protein drug substances ${ }^{8}$. Given the complexity of therapeutic proteins with respect to their large molecular size, post-translational modifications, and the variety of biological materials involved in their manufacturing process, the ability to enhance particular functional attributes while maintaining product safety and efficacy achieved through protein-engineering strategies is highly desirable.

While the integration of novel strategies and approaches to modify protein drug products is not a trivial matter $^{9}$, the potential therapeutic advantages have driven the increased use of such strategies during drug development. A number of protein-engineering platform technologies are currently in use to increase the circulating half-life, targeting, and functionality of novel therapeutic protein drugs as well as to increase production yield and product purity $(\text { Table } 1)^{5-7,10-12}$. For example, protein conjugation and derivatization approaches, including $\mathrm{Fc}$-fusion ${ }^{13,14}$, albumin-fusion ${ }^{15}$, and PEGylation ${ }^{16}$, are currently being used to extend a drug's circulating half-life ${ }^{17}$. Longer in vivo half-lives are of particular importance to patients undergoing factor/enzyme/hormone replacement therapy, in which frequent dosing regimens can result in substantial negative impacts on patient well-being in terms of ease of administration and compliance, especially in young children ${ }^{18}$. Protein-engineering approaches have also been employed to target drugs through the addition of signaling peptides or the generation of antibody-drug conjugates $^{19}$, thereby limiting toxicity and increasing drug efficacy. Additionally, exploiting particular functional characteristics of a protein drug can be accomplished through protein engineering. For example, influencing a protein's glycosylation pattern through engineering strategies can impact the protein's receptor-binding properties and overall effector function ${ }^{20,21}$. In Table 1, we have highlighted a few examples of the many technological innovations and protein-engineering platform technologies incorporated by recently approved therapeutic proteins.

\section{Overview of recently approved protein therapeutics (2011-2016*)}

Since 2011, the U.S. Food and Drug Administration Center for Drug Evaluation and Review (CDER) and the Center for Biologics Evaluation and Review (CBER) combined have approved 62 recombinant therapeutic proteins (*January 1, 2011, through August 31, 2016; "Purple Book" list of licensed biological products, including biosimilar and interchangeable biological products $^{22}$ ) (Figure 2a). Of these 62 therapeutic proteins, almost (a)

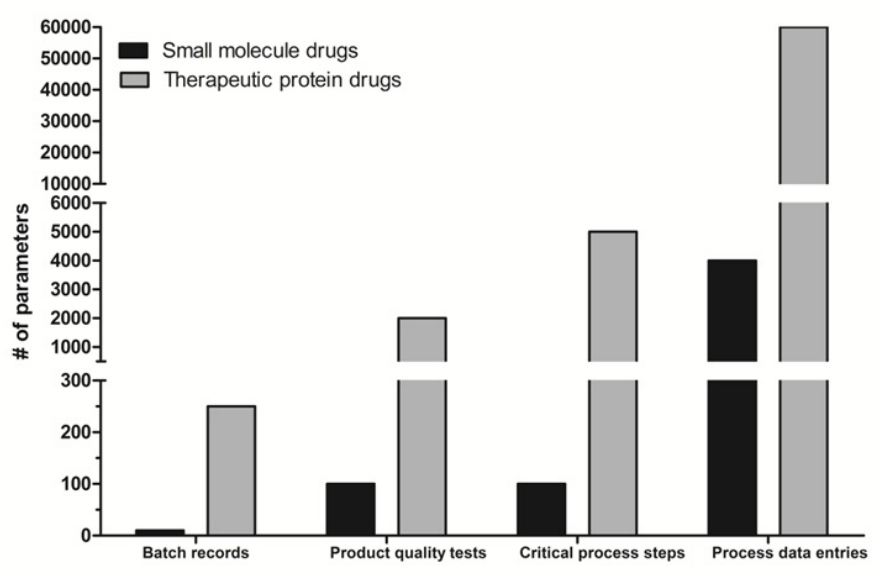

(b)

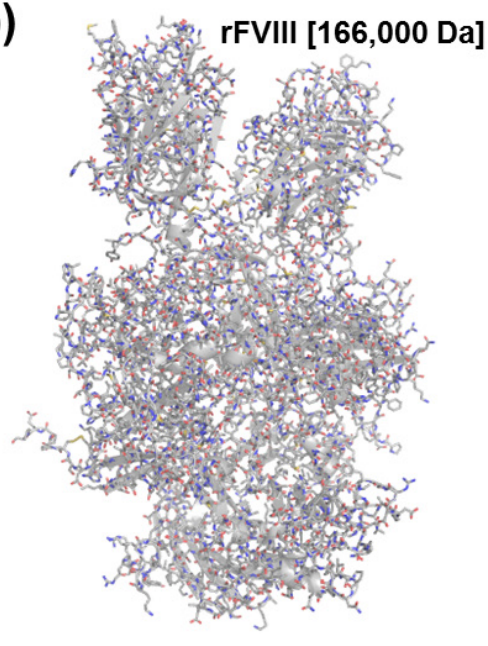

ibuprofen [206 Da]

Figure 1. Complexity of therapeutic protein drugs. (a) Graphical representation of the complexity of the manufacture of a therapeutic protein drug compared with a small-molecule drug. The number of batch records, product quality tests, critical process steps, and process data entries associated with small-molecule drugs (black) and therapeutic protein drugs (grey) as bars ${ }^{4}$. (b) Illustration depicting the differences in size and complexity of a protein therapeutic (recombinant ( $r$ ) analogue of human coagulation factor VIII (FVIII); Novoeight, Novo Nordisk; molecular weight $=166,000 \mathrm{Da}$ ) and a small-molecule drug (ibuprofen; molecular weight = $206 \mathrm{Da}$ ) by molecular model. 


\section{Table 1. Protein-engineering platform technologies.}

\begin{tabular}{|c|c|}
\hline Platform technology & Example of U.S. Food and Drug Administration-approved therapeutic protein \\
\hline \multicolumn{2}{|l|}{ Protein production technologies } \\
\hline $\begin{array}{l}\text { Production of proteins in transgenic } \\
\text { animals }^{46}\end{array}$ & C1 esterase inhibitor (Ruconest) produced in transgenic rabbit milk ${ }^{47}$ \\
\hline $\begin{array}{l}\text { Production of proteins in transgenic } \\
\text { plants }^{48}\end{array}$ & Human glucocerebrosidase (Elelyso) produced in carrot root cells $\mathrm{s}^{49,50}$ \\
\hline \multicolumn{2}{|c|}{ Rational protein structure/function technologies } \\
\hline Glyco-engineering ${ }^{20,21}$ & Humanized anti-CD20 monoclonal antibody (Gazyva) $)^{51}$ \\
\hline Fc fusion ${ }^{13,14}$ & $\begin{array}{l}\text { VEGFR Fc-fusion (Eylea) } \\
\text { CTLA-4 FC-fusion (Nulojix) } \\
\text { Glucagon-like peptide-1 receptor agonist Fc-fusion (Trulicity) } \\
\text { VEGFR Fc-fusion (Zaltrap) } \\
\text { Recombinant factor IX Fc fusion (Alprolix) } \\
\text { Recombinant factor VIII Fc-fusion (Eloctate) })^{53,54}\end{array}$ \\
\hline Albumin fusion ${ }^{15}$ & $\begin{array}{l}\text { GLP-1 receptor agonist-albumin fusion (Tanzeum) } \\
\text { Recombinant factor IX albumin fusion (Idelvion) }\end{array}$ \\
\hline PEGylation ${ }^{55}$ & $\begin{array}{l}\text { PEGylated IFN } \beta-1 a \text { (Plegridy) } \\
\text { Recombinant factor VIII PEGylated (Adynovate) }\end{array}$ \\
\hline Antibody-drug conjugates ${ }^{19}$ & $\begin{array}{l}\text { Humanized anti-HER2/neu conjugated to emtansine (Kadcyla) } \\
\text { Mouse/human chimeric anti-CD30 (Adcetris) }\end{array}$ \\
\hline mAb humanization/chimerism & $\begin{array}{l}\text { Humanized mAbs } \\
\text { Anti-human epidermal growth factor receptor } 2 \text { (HER2) (Perjeta) } \\
\text { Anti-HER2/neu conjugated to emtansine (Kadcyla) } \\
\text { Anti-IL-6 receptor (Actemra) } \\
\text { Anti-CD20 (obinutuzumab; Gazyva) } \\
\text { Anti-integrin a4b7 (LPAM-1) (Entyvio) } \\
\text { Anti-PD-1 (Keytruda) } \\
\text { Anti-dabigatran (Praxbind) } \\
\text { Anti-IL-5 (Nucala) } \\
\text { Anti-CD319 (SLAMF7) (Empliciti) } \\
\text { Anti-IL-17a (Taltz) } \\
\text { Anti-IL-5 (Cinqair) } \\
\text { Anti-PD-L1 (Tecentriq) } \\
\text { Anti-CD25 (Zinbryta) } \\
\text { Mouse/human chimeric mAbs } \\
\text { Anti-CD30 (Adcetris) } \\
\text { Anti-IL-6 (Sylvant) } \\
\text { Anti-GD2 (Unituxin) } \\
\text { Anti-Bacillus anthracis (Anthim) } \\
\text { Anti-TNF } \alpha \text { (Inflectra) }\end{array}$ \\
\hline
\end{tabular}

Listing of commonly used protein-engineering platform technologies and examples of U.S. Food and Drug Administration-approved therapeutic proteins (2011-2016, namely January 1, 2011, through August 31, 2016) that employ each strategy. CD, cluster of differentiation; CTLA-4, cytotoxic T-lymphocyte-associated protein 4; Fc, fragment crystallizable; GD2, disialoganglioside; GLP-1, glucagon-like peptide-1; HER2, human epidermal growth factor receptor 2; IFNb, interferon beta; IL, interleukin; LPAM-1, lymphocyte Peyer's Patch adhesion molecule; mAb, monoclonal antibody; PD-1, programmed death receptor-1; PD-L1, programmed death-ligand 1; PEG, polyethylene glycol; SLAMF7, SLAM family member 7; TNF $\alpha$, tumor necrosis factor alpha; VEGFR, vascular endothelial growth factor receptor. 
(a)

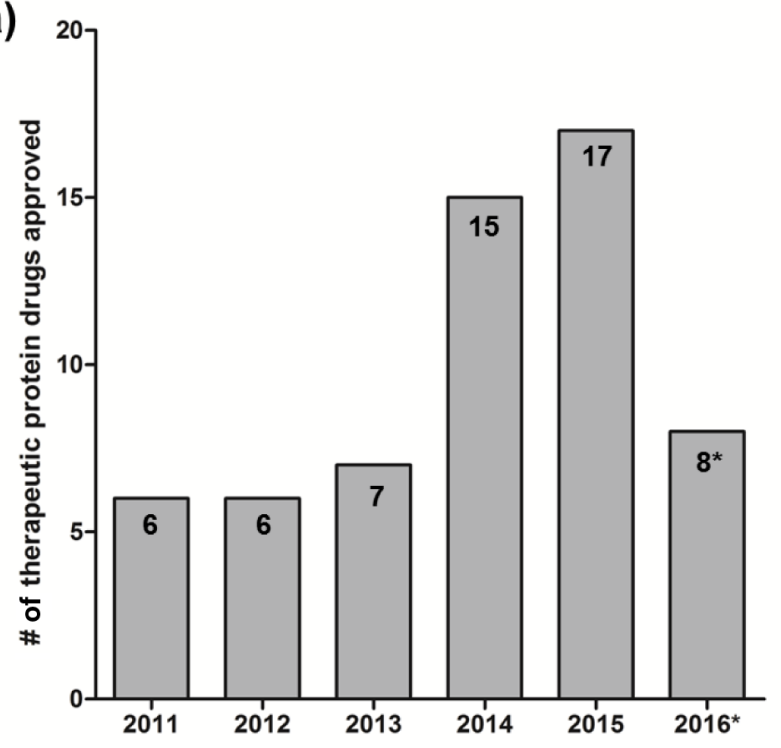

(b)

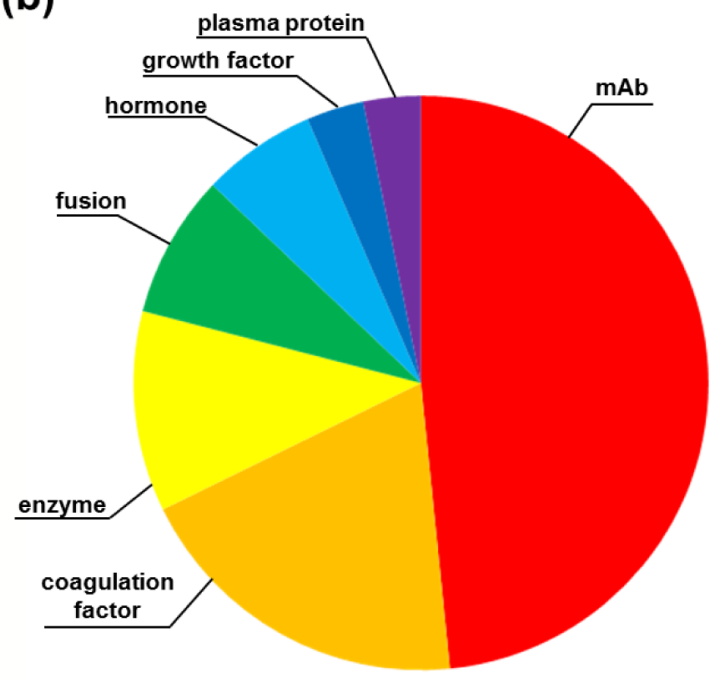

(c)

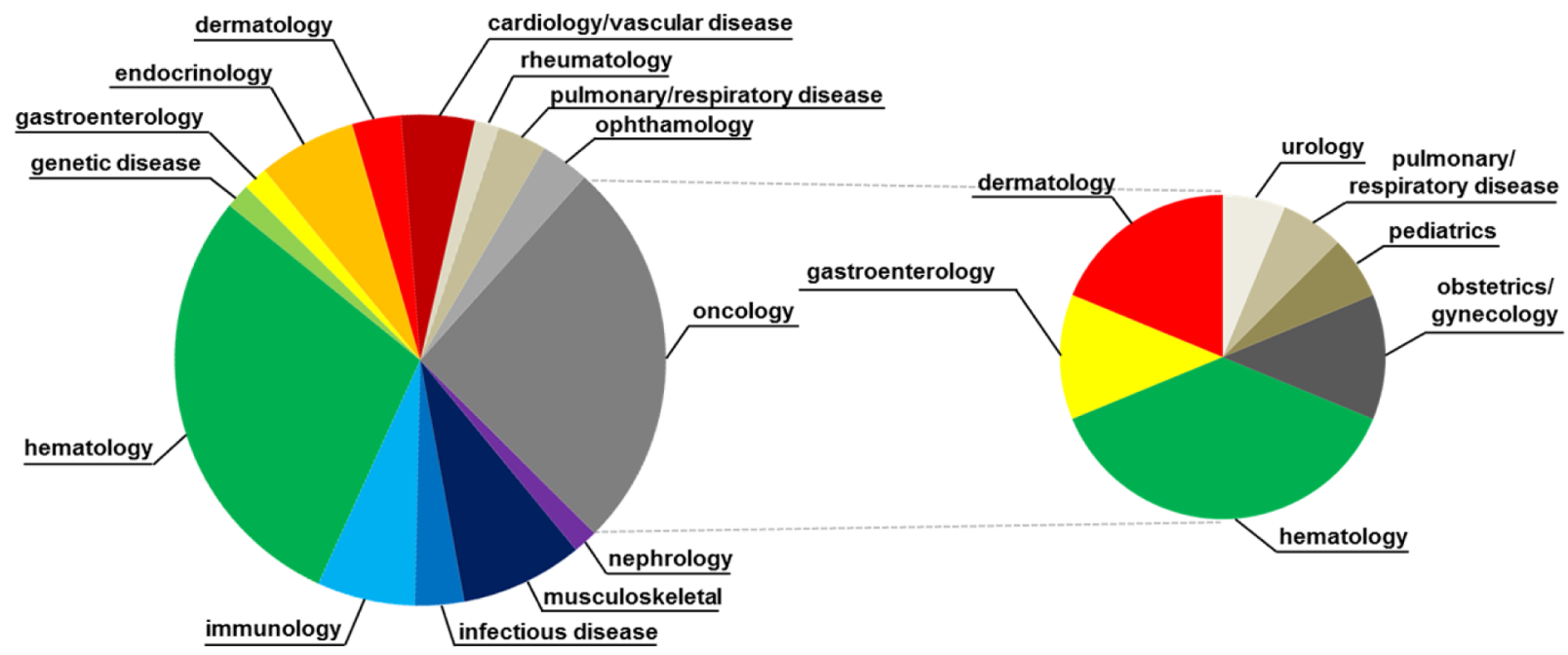

Figure 2. U.S. Food and Drug Administration (FDA)-approved therapeutic proteins (2011-2016*). (a) Bar graph showing the number of therapeutic protein FDA approvals by year $\left(2011-2016^{\star}\right)$. (b) Pie chart showing the distribution of FDA-approved therapeutic proteins (2011-2016*) by drug class. (c) (Left) Pie chart showing the distribution of FDA-approved therapeutic proteins (2011-2016*) by therapeutic area. (Right) Pie chart showing the distribution of secondary therapeutic area for oncology drugs. *January 1, 2011, through August 31 , 2016. 
half $(48 \%)$ were monoclonal antibodies (for this analysis, we included antibody-drug conjugates and antibody fragment antigen binding in this group). Coagulation factors were the next largest class $(19 \%)$ of approved protein drugs over this time period. Replacement enzymes comprised $11 \%$ of all approvals. Remaining approvals $(22 \%)$ were divided among fusion proteins, hormones, growth factors, and plasma proteins (Figure 2b). These U.S. Food and Drug Administration (FDA)-approved therapeutic proteins are indicated for a wide variety of therapeutic areas. Over half of the approved therapeutic proteins were indicated for oncology (26\%) and hematology (29\%), whereas the remaining $45 \%$ had primary indications in cardiology/vascular disease (5\%), dermatology (3\%), endocrinology $(6 \%)$, gastroenterology $(2 \%)$, genetic disease $(2 \%)$, immunology $(6 \%)$, infectious diseases (3\%), musculoskeletal $(8 \%)$, nephrology $(2 \%)$, ophthalmology $(3 \%)$, pulmonary/respiratory disease (3\%), and rheumatology (2\%) (Figure 2c, left). Of the 16 oncology drugs, six were approved to treat hematologic malignancies, whereas the remaining therapeutics were indicated for dermatology (3), gastroenterology (2), obstetrics/gynecology (2), pediatrics (1), pulmonary/respiratory disease (1), and urology (1) (Figure 2c, right). For a complete listing of the approved products, see Table 2. It is evident that recently approved therapeutic proteins serve a wide spectrum of patient populations and are of great benefit to public health.

\section{Pathways for the development of novel therapeutics}

The rapid advances in biomedical science and technology to address unmet medical needs also require that regulatory agencies ensure that such products are safe and effective. Several new pathways have emerged or have been finalized since 2011 and are summarized below (Table 3).

\section{Breakthrough therapy designation}

The Food and Drug Administration Safety and Innovation Act (FDASIA) was signed on July 9, 2012. FDASIA Section 902 provided the FDA with the ability to establish breakthrough therapy designation (BTD) as a new program within the Expedited Programs for Serious Conditions ${ }^{23}$. BTD was designed to be available for drugs intended to treat a serious condition and that have been shown to exhibit initial clinical evidence of considerable improvement over pre-existing therapies. The BTD program joined other expedited development and review programs, including fast track designation (1997), accelerated approval (1992), and priority review designation (1992), which have promoted innovation by facilitating the expedited development and review of novel medicines. Since FDASIA was signed in July 2012, CDER has approved 30 original BTDs, one third (10) of which were protein drugs. Over this same period, $26 \%$ of CDER-approved biologics (10 out of 39) have been granted BTD designation (Table 4). Since July 2012, CBER has also approved two drugs under the BTD designation, but neither of these was a recombinant protein.

\section{Orphan designation}

Rare diseases substantially impact public health, as an estimated 7,000 different disorders collectively affect approximately $10 \%$ of the U.S. population, young children particularly, and many lack effective treatments ${ }^{24}$. To promote the development of medicines that specifically address unmet medical needs, an orphan designation is given for drugs indicated for the treatment of fewer than
200,000 patients in the U.S. On June 12, 2013, the final regulations amending the 1992 Orphan Drug Regulations were issued ${ }^{25}$. These amendments clarified and instituted minor changes to regulatory language, such as defining the term "orphan subsets", the eligibility of designation for previously approved drugs, and the scope of orphan exclusive approval (https://www.gpo.gov/fdsys/ pkg/FR-2013-06-12/pdf/2013-13930.pdf). Under the Orphan Drug Act (ODA) Final Rule, orphan designation grants incentives such as orphan exclusivity for a specific indication (7-year protection from competition), thereby promoting innovation in drug development to help treat patients in greatest need of novel medicines. This program appears to have fulfilled a real need, as $50 \%$ of the recently approved therapeutic proteins (31 out of 62) were licensed under the orphan designation (Table 5).

\section{Biosimilars}

Therapeutic protein drugs are now a critical component of the overall health-care industry and have revolutionized therapy options in many disease areas. These medications, however, are also some of the most expensive in the marketplace. It had become imperative to extend the generic concept for the licensure of therapeutic protein drugs because, while there existed only a few biopharmaceuticals when the Drug Price Competition and Patent Term Restoration Act of 1984 (Waxman-Hatch Act) was passed, these now account for almost a third of pharmaceutical sales, represent a core component of modern pharmacotherapy, and include the most expensive drugs on the market ${ }^{26}$. As many biopharmaceuticals are poised to go off-patent, it has been recognized in both the U.S. and Europe that replicating the highly successful model of generic drugs to contain the costs of these therapeutics is a desirable goal, because biosimilar biological products (biosimilars) could potentially reduce the costs of therapeutic protein drugs.

In 2010, as part of the Patient Protection and Affordable Care Act (Affordable Care Act), biologics deemed to be "biosimilar" to an existing FDA-approved reference product were granted an abbreviated drug review and licensure pathway. Over the last few years, the FDA has issued several guidances to help sponsors navigate this novel regulatory pathway ${ }^{27-30}$. As of August 31, 2016, three biosimilars have been approved by the FDA (Purple Book ${ }^{22}$ ). The first FDA-approved biosimilar, filgrastim-sndz (Zarxio; Sandoz), a biosimilar of filgrastim (Neupogen; Amgen), was approved on March 6, 2015, as a leukocyte growth factor for use in several neutropenia-related indications ${ }^{31}$. This landmark approval was followed by the approval of infliximab-dyyb (Inflectra; Celltrion), a biosimilar of infliximab (Remicade; Janssen), on April 5, 2016 ${ }^{32}$, and the approval of etanercept-szzs (Erelzi; Sandoz), a biosimilar of etanercept (Enbrel; Amgen), on August 30, 2016 $6^{33}$; both are tumor necrosis factor (TNF) blockers indicated for use in inflammatory conditions. With the upcoming patent cliff approaching for several "blockbuster" therapeutic protein drugs, there is the expectation that the number of approved biosimilars will increase over the coming years. This trend has already been observed in Europe, where 21 biosimilar medicines have been authorized by the European Medicines Agency since 2006.

Although a drug product is off-patent, competitors do not get direct access to the originator company's proprietary data or to resources such as the DNA sequence or cell lines used during the 
Table 2. U.S. Food and Drug Administration-approved protein therapeutics (2011-2016).

\begin{tabular}{|c|c|c|c|}
\hline \multicolumn{4}{|c|}{ CDER approved protein therapeutics [2011-2016*] } \\
\hline $\begin{array}{l}\text { \# } \\
\text { Approval } \\
\text { Date }\end{array}$ & $\begin{array}{l}\text { Drug } \\
\text { [Market Name; Sponsor] }\end{array}$ & $\begin{array}{l}\text { Class } \\
\text { [Description] }\end{array}$ & $\begin{array}{l}\text { Therapeutic Area } \\
\text { [General Indication] }\end{array}$ \\
\hline $\begin{array}{l}1 \\
3 / 9 / 2011\end{array}$ & $\begin{array}{l}\text { belimumab } \\
\text { [Benlysta; Human } \\
\text { Genome Sciences] }\end{array}$ & $\begin{array}{l}\text { mAb } \\
\text { [human anti-B-cell activating } \\
\text { factor (BAFF)] }\end{array}$ & $\begin{array}{l}\text { immunology } \\
\text { [autoimmunity (lupus)] }\end{array}$ \\
\hline $\begin{array}{l}\mathbf{2} \\
3 / 25 / 2011\end{array}$ & $\begin{array}{l}\text { ipilimumab } \\
\text { [Yervoy; Bristol Myers } \\
\text { Squibb] }\end{array}$ & $\begin{array}{l}\text { mAb } \\
\text { [human anti-CTLA-4] }\end{array}$ & $\begin{array}{l}\text { dermatology/oncology } \\
\text { [cancer (melanoma)] }\end{array}$ \\
\hline $\begin{array}{l}3 \\
6 / 15 / 2011\end{array}$ & $\begin{array}{l}\text { belatacept } \\
\text { [Nulojix; Bristol Myers } \\
\text { Squibb] }\end{array}$ & $\begin{array}{l}\text { Fc fusion } \\
\text { [CTLA-4 Fc-fusion] }\end{array}$ & $\begin{array}{l}\text { immunology/nephrology } \\
\text { [transplant rejection (kidney)] }\end{array}$ \\
\hline $\begin{array}{l}\mathbf{4} \\
8 / 19 / 2011\end{array}$ & $\begin{array}{l}\text { brentuximab vedotin } \\
\text { [Adcetris; Seattle Genetics] }\end{array}$ & $\begin{array}{l}\text { antibody-drug conjugate } \\
\text { [mouse/human chimeric anti- } \\
\text { CD30] }\end{array}$ & $\begin{array}{l}\text { hematology/oncology } \\
\text { [cancer (lymphoma)] }\end{array}$ \\
\hline $\begin{array}{l}\mathbf{5} \\
11 / 18 / 2011\end{array}$ & $\begin{array}{l}\text { afilbercept } \\
\text { [Eylea; Regeneron } \\
\text { Pharmaceuticals] }\end{array}$ & $\begin{array}{l}\text { Fc fusion } \\
\text { [VEGFR FC-fusion] }\end{array}$ & $\begin{array}{l}\text { ophthalmology } \\
\text { [macular degeneration] }\end{array}$ \\
\hline $\begin{array}{l}6 \\
11 / 18 / 2011\end{array}$ & $\begin{array}{l}\text { asparaginase erwinia } \\
\text { chrysanthemi } \\
\text { [Erwinaze; Jazz } \\
\text { Pharmaceuticals] }\end{array}$ & $\begin{array}{l}\text { enzyme } \\
\text { [asparaginase erwinia } \\
\text { chrysanthemi] }\end{array}$ & $\begin{array}{l}\text { hematology/oncology } \\
\text { [cancer (leukemia)] }\end{array}$ \\
\hline $\begin{array}{l}7 \\
1 / 17 / 2012\end{array}$ & $\begin{array}{l}\text { glucarpidase } \\
\text { [Voraxaze; BTG } \\
\text { International] }\end{array}$ & $\begin{array}{l}\text { enzyme } \\
\text { [glucarpidase] }\end{array}$ & $\begin{array}{l}\text { nephrology } \\
\text { [kidney failure] }\end{array}$ \\
\hline $\begin{array}{l}8 \\
5 / 1 / 2012\end{array}$ & $\begin{array}{l}\text { taliglucerase alfa } \\
\text { [Elelyso; Pfizer] }\end{array}$ & $\begin{array}{l}\text { enzyme } \\
\text { [ } \beta \text {-glucocerebrosidase }]\end{array}$ & $\begin{array}{l}\text { endocrinology/gastroenterology } \\
\text { [genetic disorder (Gaucher)] }\end{array}$ \\
\hline $\begin{array}{l}\mathbf{9} \\
6 / 8 / 2012\end{array}$ & $\begin{array}{l}\text { pertuzumab } \\
\text { [Perjeta; Genentech] }\end{array}$ & $\begin{array}{l}\text { mAb } \\
\text { [humanized anti-human } \\
\text { epidermal growth factor } \\
\text { receptor } 2 \text { (HER2)] }\end{array}$ & $\begin{array}{l}\text { obstetrics, gynecology/oncology } \\
\text { [cancer (breast)] }\end{array}$ \\
\hline $\begin{array}{l}10 \\
8 / 3 / 2012\end{array}$ & $\begin{array}{l}\text { ziv-afilbercept } \\
\text { [Zaltrap; Sanofi-Aventis } \\
\text { U.S.] }\end{array}$ & $\begin{array}{l}\text { Fc fusion } \\
\text { [VEGFR Fc fusion] }\end{array}$ & $\begin{array}{l}\text { gastroenterology/oncology } \\
\text { [cancer (colorectal)] }\end{array}$ \\
\hline $\begin{array}{l}11 \\
8 / 29 / 2012\end{array}$ & $\begin{array}{l}\text { tbo-filgrastim } \\
\text { [Granix; Cephalon] }\end{array}$ & $\begin{array}{l}\text { growth factor } \\
\text { [G-CSF] }\end{array}$ & $\begin{array}{l}\text { hematology/oncology } \\
\text { [neutropenia] }\end{array}$ \\
\hline $\begin{array}{l}12 \\
10 / 17 / 2012\end{array}$ & $\begin{array}{l}\text { ocriplasmin } \\
\text { [Jetrea; ThromboGenics] }\end{array}$ & $\begin{array}{l}\text { enzyme } \\
\text { [ocriplasmin] }\end{array}$ & $\begin{array}{l}\text { ophthalmology } \\
\text { [eye condition (symptomatic vitreomacular } \\
\text { adhesion)] }\end{array}$ \\
\hline $\begin{array}{l}\mathbf{1 3} \\
12 / 14 / 2012\end{array}$ & $\begin{array}{l}\text { raxibacumab } \\
\text { [raxibacumab; Human } \\
\text { Genome Sciences] }\end{array}$ & $\begin{array}{l}\text { mAb } \\
\text { [human anti-anthrax protective } \\
\text { antigen (PA)] }\end{array}$ & $\begin{array}{l}\text { infections and infectious disease } \\
\text { [infectious disease (inhalational anthrax)] }\end{array}$ \\
\hline $\begin{array}{l}14 \\
2 / 22 / 2013\end{array}$ & $\begin{array}{l}\text { ado-trastuzumab } \\
\text { emtansine } \\
\text { [Kadcyla; Genentech] }\end{array}$ & $\begin{array}{l}\text { antibody-drug conjugate } \\
\text { [humanized anti-HER2/neu } \\
\text { conjugated to emtansine] }\end{array}$ & $\begin{array}{l}\text { obstetrics, gynecology/oncology } \\
\text { [cancer (breast)] }\end{array}$ \\
\hline $\begin{array}{l}15 \\
7 / 18 / 2013\end{array}$ & $\begin{array}{l}\text { golimumab injection, for } \\
\text { IV use } \\
\text { [Simponi Aria; Janssen } \\
\text { Biotech] }\end{array}$ & $\begin{array}{l}\text { mAb } \\
{[\text { human anti-TNF } \alpha]}\end{array}$ & $\begin{array}{l}\text { musculoskeletal/rheumatology } \\
\text { [autoimmunity (rheumatoid arthritis)] }\end{array}$ \\
\hline $\begin{array}{l}\mathbf{1 6} \\
10 / 21 / 2013\end{array}$ & $\begin{array}{l}\text { tocilizumab } \\
\text { [Actemra; Genentech] }\end{array}$ & $\begin{array}{l}\text { mAb } \\
\text { [humanized anti-IL-6 receptor] }\end{array}$ & $\begin{array}{l}\text { musculoskeletal/rheumatology } \\
\text { [autoimmunity (rheumatoid arthritis; } \\
\text { juvenile idiopathic arthritis)] }\end{array}$ \\
\hline
\end{tabular}




\begin{tabular}{|c|c|c|c|}
\hline \multicolumn{4}{|c|}{ CDER approved protein therapeutics [2011-2016*] } \\
\hline $\begin{array}{l}\# \\
\text { Approval } \\
\text { Date }\end{array}$ & $\begin{array}{l}\text { Drug } \\
\text { [Market Name; Sponsor] }\end{array}$ & $\begin{array}{l}\text { Class } \\
\text { [Description] }\end{array}$ & $\begin{array}{l}\text { Therapeutic Area } \\
\text { [General Indication] }\end{array}$ \\
\hline $\begin{array}{l}17 \\
11 / 1 / 2013\end{array}$ & $\begin{array}{l}\text { obinutuzumab } \\
\text { [Gazyva; Genentech] }\end{array}$ & $\begin{array}{l}\text { mAb } \\
\text { [humanized anti-CD20] }\end{array}$ & $\begin{array}{l}\text { hematology/oncology } \\
\text { [cancer (leukemia)] }\end{array}$ \\
\hline $\begin{array}{l}18 \\
2 / 14 / 2014\end{array}$ & $\begin{array}{l}\text { elosulfase alfa } \\
\text { [Vimizim; BioMarin } \\
\text { Pharmaceutical] }\end{array}$ & $\begin{array}{l}\text { enzyme } \\
\text { [elosulfase alfa] }\end{array}$ & $\begin{array}{l}\text { musculoskeletal/genetic disease } \\
\text { [genetic disorder (Morquio A)] }\end{array}$ \\
\hline $\begin{array}{l}19 \\
2 / 24 / 2014\end{array}$ & $\begin{array}{l}\text { metreleptin } \\
\text { [Myalept; Amylin } \\
\text { Pharmaceuticals] }\end{array}$ & $\begin{array}{l}\text { hormone } \\
\text { [metreleptin] }\end{array}$ & $\begin{array}{l}\text { immunology } \\
\text { [lipodystrophy] }\end{array}$ \\
\hline $\begin{array}{l}20 \\
4 / 15 / 2014\end{array}$ & $\begin{array}{l}\text { albiglutide } \\
\text { [Tanzeum; } \\
\text { GlaxoSmithKline] }\end{array}$ & $\begin{array}{l}\text { albumin fusion/hormone } \\
\text { [glucagon-like peptide-1 } \\
\text { dimer albumin fusion] }\end{array}$ & $\begin{array}{l}\text { endocrinology } \\
\text { [diabetes (type 2)] }\end{array}$ \\
\hline $\begin{array}{l}21 \\
4 / 21 / 2014\end{array}$ & $\begin{array}{l}\text { ramucirumab } \\
\text { [Cyramza; Eli Lilly and } \\
\text { Company] }\end{array}$ & $\begin{array}{l}\text { mAb } \\
\text { [human anti-VEGFR2 (KDR)] }\end{array}$ & $\begin{array}{l}\text { gastroenterology/oncology } \\
\text { [cancer (stomach; gastroesophageal } \\
\text { junction)] }\end{array}$ \\
\hline $\begin{array}{l}22 \\
4 / 23 / 2014\end{array}$ & $\begin{array}{l}\text { siltuximab } \\
\text { [Sylvant; Janssen } \\
\text { Biotech] }\end{array}$ & $\begin{array}{l}\text { mAb } \\
\text { [mouse/human chimeric anti- } \\
\text { IL-6] }\end{array}$ & $\begin{array}{l}\text { hematology/immunology } \\
\text { [multicentric Castleman's disease] }\end{array}$ \\
\hline $\begin{array}{l}23 \\
5 / 20 / 2014\end{array}$ & $\begin{array}{l}\text { vedolizumab } \\
\text { [Entyvio; Takeda } \\
\text { Pharmaceuticals } \\
\text { America] }\end{array}$ & $\begin{array}{l}\text { mAb } \\
\text { [humanized anti-integrin a4b7 } \\
\text { (lymphocyte Peyer's Patch } \\
\text { adhesion molecule; LPAM-1)] }\end{array}$ & $\begin{array}{l}\text { gastroenterology/immunology } \\
\text { [inflammatory (ulcerative colitis/Crohn's } \\
\text { disease)] }\end{array}$ \\
\hline $\begin{array}{l}24 \\
8 / 15 / 2014\end{array}$ & $\begin{array}{l}\text { peginterferon beta-1a } \\
\text { [Plegridy; Biogen Idec] }\end{array}$ & $\begin{array}{l}\text { cytokine } \\
\text { [PEGylated IFNb-1b] }\end{array}$ & $\begin{array}{l}\text { immunology/musculoskeletal } \\
\text { [multiple sclerosis] }\end{array}$ \\
\hline $\begin{array}{l}25 \\
9 / 4 / 2014\end{array}$ & $\begin{array}{l}\text { pembrolizumab } \\
\text { [Keytruda; Merck Sharp \& } \\
\text { Dohme] }\end{array}$ & $\begin{array}{l}\text { mAb } \\
\text { [humanized anti-PD-1] }\end{array}$ & $\begin{array}{l}\text { dermatology/oncology } \\
\text { [cancer (melanoma)] }\end{array}$ \\
\hline $\begin{array}{l}26 \\
9 / 18 / 2014\end{array}$ & $\begin{array}{l}\text { dulaglutide } \\
\text { [Trulicity; Eli Lilly and } \\
\text { Company] }\end{array}$ & $\begin{array}{l}\text { Fc fusion } \\
\text { [glucagon-like peptide- } 1 \\
\text { receptor agonist] }\end{array}$ & $\begin{array}{l}\text { endocrinology } \\
\text { [diabetes (type 2)] }\end{array}$ \\
\hline $\begin{array}{l}27 \\
12 / 3 / 2014\end{array}$ & $\begin{array}{l}\text { blintumomab } \\
\text { [Blincyto; Amgen] }\end{array}$ & $\begin{array}{l}\text { mAb } \\
\text { [mouse bispecific anti-CD19/ } \\
\text { anti-CD3] }\end{array}$ & $\begin{array}{l}\text { hematology/oncology } \\
\text { [cancer (leukemia)] }\end{array}$ \\
\hline $\begin{array}{l}\mathbf{2 8} \\
12 / 22 / 2014\end{array}$ & $\begin{array}{l}\text { nivolumab } \\
\text { [Opdivo; Bristol Myers } \\
\text { Squibb] }\end{array}$ & $\begin{array}{l}\text { mAb } \\
\text { [human anti-PD-1] }\end{array}$ & $\begin{array}{l}\text { dermatology/oncology } \\
\text { [cancer (melanoma)] }\end{array}$ \\
\hline $\begin{array}{l}29 \\
1 / 21 / 2015\end{array}$ & $\begin{array}{l}\text { secukinumab } \\
\text { [Cosentyx; Novartis } \\
\text { Pharmaceuticals] }\end{array}$ & $\begin{array}{l}\text { mAb } \\
\text { [human anti-IL-17A] }\end{array}$ & $\begin{array}{l}\text { dermatology/immunology } \\
\text { [autoimmunity (plaque psoriasis)] }\end{array}$ \\
\hline $\begin{array}{l}30 \\
1 / 23 / 2015\end{array}$ & $\begin{array}{l}\text { parathyroid hormone } \\
\text { [Natpara; NPS } \\
\text { Pharmaceuticals] }\end{array}$ & $\begin{array}{l}\text { hormone } \\
\text { [parathyroid hormone] }\end{array}$ & $\begin{array}{l}\text { endocrinology/hematology } \\
\text { [hypoparathyroidism] }\end{array}$ \\
\hline $\begin{array}{l}31 \\
3 / 6 / 2015\end{array}$ & $\begin{array}{l}\text { filgrastim-sndz } \\
\text { [Zarxio; Sandoz] }\end{array}$ & $\begin{array}{l}\text { growth factor } \\
\text { [G-CSF] }\end{array}$ & $\begin{array}{l}\text { hematology/oncology } \\
\text { [neutropenia] }\end{array}$ \\
\hline $\begin{array}{l}32 \\
3 / 10 / 2015\end{array}$ & $\begin{array}{l}\text { dinutuximab } \\
\text { [Unituxin; United } \\
\text { Therapeutics] }\end{array}$ & $\begin{array}{l}\text { mAb } \\
\text { [mouse/human chimeric anti- } \\
\text { GD2] }\end{array}$ & $\begin{array}{l}\text { oncology/pediatrics/neonatalogy } \\
\text { [cancer (neuroblastoma)] }\end{array}$ \\
\hline $\begin{array}{l}33 \\
7 / 24 / 2015\end{array}$ & $\begin{array}{l}\text { alirocumab } \\
\text { [Praluent; Sanofi-Aventis } \\
\text { U.S.] }\end{array}$ & $\begin{array}{l}\text { mAb } \\
\text { [human anti-proprotein } \\
\text { convertase substilisin/kexin } \\
\text { type } 9 \text { (PCSK9)] }\end{array}$ & $\begin{array}{l}\text { cardiology/vascular diseases } \\
\text { [high cholesterol] }\end{array}$ \\
\hline
\end{tabular}




\begin{tabular}{|c|c|c|c|}
\hline \multicolumn{4}{|c|}{ CDER approved protein therapeutics [2011-2016*] } \\
\hline $\begin{array}{l}\# \\
\text { Approval } \\
\text { Date }\end{array}$ & $\begin{array}{l}\text { Drug } \\
\text { [Market Name; Sponsor] }\end{array}$ & $\begin{array}{l}\text { Class } \\
\text { [Description] }\end{array}$ & $\begin{array}{l}\text { Therapeutic Area } \\
\text { [General Indication] }\end{array}$ \\
\hline $\begin{array}{l}34 \\
8 / 27 / 2015\end{array}$ & $\begin{array}{l}\text { evolocumab } \\
\text { [Repatha; Amgen] }\end{array}$ & $\begin{array}{l}\text { mAb } \\
\text { [human anti-proprotein } \\
\text { convertase substilisin/kexin } \\
\text { type } 9 \text { (PCSK9)] }\end{array}$ & $\begin{array}{l}\text { cardiology/vascular diseases } \\
\text { [high cholesterol] }\end{array}$ \\
\hline $\begin{array}{l}35 \\
10 / 16 / 2015\end{array}$ & $\begin{array}{l}\text { idarucizumab } \\
\text { [Praxbind; } \\
\text { Boehringer Ingelheim } \\
\text { Pharmaceuticals] }\end{array}$ & $\begin{array}{l}\text { Fab } \\
\text { [humanized anti-dabigatran] }\end{array}$ & $\begin{array}{l}\text { hematology } \\
\text { [anticoagulant reversal] }\end{array}$ \\
\hline $\begin{array}{l}36 \\
10 / 23 / 2015\end{array}$ & $\begin{array}{l}\text { asfotase-alfa } \\
\text { [Strensiq; Alexion } \\
\text { Pharmaceuticals] }\end{array}$ & $\begin{array}{l}\text { Fc fusion/enzyme } \\
\text { [tissue non-specific alkaline } \\
\text { phosphatase/Fc fusion/deca- } \\
\text { asparatate (D10) peptide] }\end{array}$ & $\begin{array}{l}\text { genetic disease/pediatrics/neonatalogy } \\
\text { [genetic disorder (hypophosphatasia)] }\end{array}$ \\
\hline $\begin{array}{l}37 \\
11 / 4 / 2015\end{array}$ & $\begin{array}{l}\text { mepolizumab } \\
\text { [Nucala; GlaxoSmithKline] }\end{array}$ & $\begin{array}{l}\text { mAb } \\
\text { [humanized anti-IL-5] }\end{array}$ & $\begin{array}{l}\text { pulmonary/respiratory disease } \\
\text { [asthma] }\end{array}$ \\
\hline $\begin{array}{l}38 \\
11 / 16 / 2015\end{array}$ & $\begin{array}{l}\text { daratumumab } \\
\text { [Darzalex; Janssen } \\
\text { Biotech] }\end{array}$ & $\begin{array}{l}\text { mAb } \\
\text { [human anti-CD38] }\end{array}$ & $\begin{array}{l}\text { hematology/oncology } \\
\text { [cancer (multiple myeloma)] }\end{array}$ \\
\hline $\begin{array}{l}39 \\
11 / 24 / 2015\end{array}$ & $\begin{array}{l}\text { necitumumab } \\
\text { [Portrazza; Eli Lilly and } \\
\text { Company] }\end{array}$ & $\begin{array}{l}\text { mAb } \\
\text { [human anti-epidermal growth } \\
\text { factor receptor (EGFR)] }\end{array}$ & $\begin{array}{l}\text { pulmonary/respiratory disease/oncology } \\
\text { [cancer (lung)] }\end{array}$ \\
\hline $\begin{array}{l}40 \\
11 / 30 / 2015\end{array}$ & $\begin{array}{l}\text { elotuzumab } \\
\text { [Empliciti; Bristol Myers } \\
\text { Squibb] }\end{array}$ & $\begin{array}{l}\text { mAb } \\
\text { [humanized anti- } \\
\text { CD319(SLAMF7)] }\end{array}$ & $\begin{array}{l}\text { oncology } \\
\text { [cancer (multiple myeloma)] }\end{array}$ \\
\hline $\begin{array}{l}\mathbf{4 1} \\
12 / 8 / 2015\end{array}$ & $\begin{array}{l}\text { sebelipase alfa } \\
\text { [Kanuma; Alexion } \\
\text { Pharmaceuticals] }\end{array}$ & $\begin{array}{l}\text { enzyme } \\
\text { [lysosomal acid lipase] }\end{array}$ & $\begin{array}{l}\text { cardiology/vascular diseases/genetic } \\
\text { disease } \\
\text { [lysosomal acid lipase deficiency] }\end{array}$ \\
\hline $\begin{array}{l}42 \\
3 / 18 / 2016\end{array}$ & $\begin{array}{l}\text { obiltoxaximab } \\
\text { [Anthim; Elusys } \\
\text { Therapeutics] }\end{array}$ & $\begin{array}{l}\text { mAb } \\
\text { [mouse/human chimeric anti- } \\
\text { Bacillus anthracis] }\end{array}$ & $\begin{array}{l}\text { infections and infectious disease } \\
\text { [infectious disease (inhalational anthrax)] }\end{array}$ \\
\hline $\begin{array}{l}43 \\
3 / 22 / 2016\end{array}$ & $\begin{array}{l}\text { ixekizumab } \\
\text { [Taltz; Eli Lilly and } \\
\text { Company] }\end{array}$ & $\begin{array}{l}\text { mAb } \\
\text { [humanized anti-IL-17a] }\end{array}$ & $\begin{array}{l}\text { dermatology/immunology } \\
\text { [autoimmunity (plaque psoriasis)] }\end{array}$ \\
\hline $\begin{array}{l}44 \\
3 / 23 / 2016\end{array}$ & $\begin{array}{l}\text { reslizumab } \\
\text { [Cinqair; Teva } \\
\text { Respiratory] }\end{array}$ & $\begin{array}{l}\text { mAb } \\
\text { [humanized anti-IL-5] }\end{array}$ & $\begin{array}{l}\text { pulmonary/respiratory disease } \\
\text { [asthma] }\end{array}$ \\
\hline $\begin{array}{l}45 \\
4 / 5 / 2016\end{array}$ & $\begin{array}{l}\text { infliximab-dyyb } \\
\text { [Inflectra; Celltrion] }\end{array}$ & $\begin{array}{l}\text { mAb } \\
\text { [mouse/human chimeric anti- } \\
\text { TNF } \alpha]\end{array}$ & $\begin{array}{l}\text { musculoskeletal/rheumatology } \\
\text { [inflammatory (Crohn's disease/ulcerative } \\
\text { colitis/rheumatoid arthritis/ankylosing } \\
\text { spondylitis/psoriatic arthritis/plaque } \\
\text { psoriasis)] }\end{array}$ \\
\hline $\begin{array}{l}46 \\
5 / 18 / 2016\end{array}$ & $\begin{array}{l}\text { atezolizumab } \\
\text { [Tecentriq; Genentech] }\end{array}$ & $\begin{array}{l}\text { mAb } \\
\text { [humanized anti-PD-L1] }\end{array}$ & $\begin{array}{l}\text { urology/oncology } \\
\text { [cancer (bladder)] }\end{array}$ \\
\hline $\begin{array}{l}47 \\
5 / 27 / 2016\end{array}$ & $\begin{array}{l}\text { daclizumab } \\
\text { [Zinbryta; Biogen] }\end{array}$ & $\begin{array}{l}\text { mAb } \\
\text { [humanized anti-CD25] }\end{array}$ & $\begin{array}{l}\text { musculoskeletal/neurology } \\
\text { [multiple sclerosis] }\end{array}$ \\
\hline $\begin{array}{l}48 \\
8 / 30 / 2016\end{array}$ & $\begin{array}{l}\text { etanercept-szzs } \\
\text { [Erelzi; Sandoz] }\end{array}$ & $\begin{array}{l}\text { Fc fusion } \\
\text { [TNFR FC-fusion] }\end{array}$ & $\begin{array}{l}\text { rheumatology } \\
\text { [inflammatory (rheumatoid } \\
\text { arthritis/juvenile idiopathic } \\
\text { arthritis/psoriatic arthritis/ankylosing } \\
\text { spondylitis/plaque psoriasis)] }\end{array}$ \\
\hline
\end{tabular}




\begin{tabular}{|c|c|c|c|}
\hline \multicolumn{4}{|c|}{ CBER approved protein therapeutics [2011-2016*] } \\
\hline $\begin{array}{l}\text { \# } \\
\text { Approval } \\
\text { Date }\end{array}$ & $\begin{array}{l}\text { Drug Name } \\
\text { [Market Name; Sponsor] }\end{array}$ & $\begin{array}{l}\text { Class } \\
\text { Description }\end{array}$ & Therapeutic Area \\
\hline $\begin{array}{l}1 \\
6 / 26 / 2013\end{array}$ & $\begin{array}{l}\text { coagulation factor IX } \\
\text { recombinant human } \\
\text { [Rixubis; Baxter } \\
\text { Healthcare] }\end{array}$ & $\begin{array}{l}\text { coagulation factor } \\
\text { [recombinant factor IX] }\end{array}$ & $\begin{array}{l}\text { hematology } \\
\text { [hemophilia B] }\end{array}$ \\
\hline $\begin{array}{l}2 \\
10 / 15 / 2013\end{array}$ & $\begin{array}{l}\text { antihemophilic factor } \\
\text { (recombinant) } \\
\text { [Novoeight; Novo } \\
\text { Nordisk] }\end{array}$ & $\begin{array}{l}\text { coagulation factor } \\
\text { [recombinant factor VIII] }\end{array}$ & $\begin{array}{l}\text { hematology } \\
\text { [hemophilia A] }\end{array}$ \\
\hline $\begin{array}{l}3 \\
12 / 23 / 2013\end{array}$ & $\begin{array}{l}\text { coagulation factor XIII A- } \\
\text { subunit (recombinant) } \\
\text { [Tretten; Novo Nordisk] }\end{array}$ & $\begin{array}{l}\text { coagulation factor } \\
\text { [recombinant factor XIII A } \\
\text { subunit] }\end{array}$ & $\begin{array}{l}\text { hematology } \\
\text { [congenital factor XIII deficiency] }\end{array}$ \\
\hline $\begin{array}{l}4 \\
3 / 28 / 2014\end{array}$ & $\begin{array}{l}\text { coagulation factor IX } \\
\text { (recombinant), Fc fusion } \\
\text { protein } \\
\text { [Alprolix; Biogen] }\end{array}$ & $\begin{array}{l}\text { Fc fusion/coagulation factor } \\
\text { [recombinant factor IX Fc- } \\
\text { fusion] }\end{array}$ & $\begin{array}{l}\text { hematology } \\
\text { [hemophilia B] }\end{array}$ \\
\hline $\begin{array}{l}\mathbf{5} \\
6 / 6 / 2014\end{array}$ & $\begin{array}{l}\text { antihemophilic factor } \\
\text { (recombinant), Fc fusion } \\
\text { protein } \\
\text { [Eloctate; Biogen] }\end{array}$ & $\begin{array}{l}\text { Fc fusion/coagulation factor } \\
\text { [recombinant factor VIII Fc- } \\
\text { fusion] }\end{array}$ & $\begin{array}{l}\text { hematology } \\
\text { [hemophilia A] }\end{array}$ \\
\hline $\begin{array}{l}6 \\
7 / 16 / 2014\end{array}$ & $\begin{array}{l}\text { C1 esterase inhibitor } \\
\text { recombinant } \\
\text { [Ruconest; Salix } \\
\text { Pharmaceuticals] }\end{array}$ & $\begin{array}{l}\text { plasma protein } \\
\text { [recombinant C1 esterase } \\
\text { inhibitor] }\end{array}$ & $\begin{array}{l}\text { hematology } \\
\text { [hereditary angioedema] }\end{array}$ \\
\hline $\begin{array}{l}7 \\
10 / 23 / 2014\end{array}$ & $\begin{array}{l}\text { antihemophilic factor } \\
\text { porcine, B-domain } \\
\text { truncated recombinant } \\
\text { [Obizur; Baxter } \\
\text { Healthcare] }\end{array}$ & $\begin{array}{l}\text { coagulation factor } \\
\text { [recombinant factor VIII } \\
\text { (porcine)] }\end{array}$ & $\begin{array}{l}\text { hematology } \\
\text { [hemophilia A] }\end{array}$ \\
\hline $\begin{array}{l}8 \\
4 / 29 / 2015\end{array}$ & $\begin{array}{l}\text { coagulation factor IX } \\
\text { (recombinant) } \\
\text { [Ixinity; Cangene } \\
\text { BioPharma] }\end{array}$ & $\begin{array}{l}\text { coagulation factor } \\
\text { [recombinant factor IX] }\end{array}$ & $\begin{array}{l}\text { hematology } \\
\text { [hemophilia B] }\end{array}$ \\
\hline $\begin{array}{l}9 \\
9 / 4 / 2015\end{array}$ & $\begin{array}{l}\text { antihemophilic factor } \\
\text { (recombinant) } \\
\text { [Nuwiq; Octapharma } \\
\text { USA] }\end{array}$ & $\begin{array}{l}\text { coagulation factor } \\
\text { [recombinant factor VIII] }\end{array}$ & $\begin{array}{l}\text { hematology } \\
\text { [hemophilia A] }\end{array}$ \\
\hline $\begin{array}{l}10 \\
11 / 13 / 2015\end{array}$ & $\begin{array}{l}\text { antihemophilic factor } \\
\text { (recombinant) PEGylated } \\
\text { [Adynovate; Baxalta US] }\end{array}$ & $\begin{array}{l}\text { coagulation factor } \\
\text { [recombinant factor VIII } \\
\text { PEGylated] }\end{array}$ & $\begin{array}{l}\text { hematology } \\
\text { [hemophilia A] }\end{array}$ \\
\hline $\begin{array}{l}11 \\
12 / 8 / 2015\end{array}$ & $\begin{array}{l}\text { von Willebrand factor } \\
\text { (recombinant) } \\
\text { [Vonvendi; Baxalta US] }\end{array}$ & $\begin{array}{l}\text { plasma protein } \\
\text { [recombinant VWF] }\end{array}$ & $\begin{array}{l}\text { hematology } \\
\text { [von Willebrand disease] }\end{array}$ \\
\hline $\begin{array}{l}12 \\
3 / 4 / 2016\end{array}$ & $\begin{array}{l}\text { coagulation factor IX } \\
\text { recombinant human } \\
\text { [Idelvion; CSL Behring } \\
\text { Recombinant] }\end{array}$ & $\begin{array}{l}\text { coagulation factor } \\
\text { [recombinant factor IX albumin } \\
\text { fusion] }\end{array}$ & $\begin{array}{l}\text { hematology } \\
\text { [hemophilia B] }\end{array}$ \\
\hline $\begin{array}{l}13 \\
3 / 16 / 2016\end{array}$ & $\begin{array}{l}\text { antihemophilic factor } \\
\text { (recombinant) } \\
\text { [Kovaltry; Bayer } \\
\text { HealthCare] }\end{array}$ & $\begin{array}{l}\text { coagulation factor } \\
\text { [recombinant factor VIII full- } \\
\text { length] }\end{array}$ & $\begin{array}{l}\text { hematology } \\
\text { [hemophilia A] }\end{array}$ \\
\hline $\begin{array}{l}14 \\
5 / 25 / 2016\end{array}$ & $\begin{array}{l}\text { antihemophilic factor } \\
\text { (recombinant) } \\
\text { [Afstyla; CSL Behring] }\end{array}$ & $\begin{array}{l}\text { coagulation factor } \\
\text { [recombinant factor VIII] }\end{array}$ & $\begin{array}{l}\text { hematology } \\
\text { [hemophilia A] }\end{array}$ \\
\hline
\end{tabular}

Comprehensive listing of all FDA-approved therapeutic proteins granted orphan designation upon original submission from January 1 , 2011, through August 31, 2016, listed in chronological order of FDA approval. In addition, the class of protein, a brief description, and orphan designation are included. CD, cluster of differentiation; CTLA-4, cytotoxic T-lymphocyte-associated protein 4; Fab, fragment antigen binding; Fc, fragment crystallizable; GD2, disialoganglioside; IL, interleukin; mAb, monoclonal antibody; PD-1, programmed death receptor-1; VEGFR, vascular endothelial growth factor receptor. 
Table 3. Pathways for the development of novel therapeutics.

\begin{tabular}{|c|c|}
\hline Pathway & Description and relevant U.S. Food and Drug Administration (FDA) guidances \\
\hline $\begin{array}{l}\text { Breakthrough } \\
\text { therapy } \\
\text { designation }\end{array}$ & $\begin{array}{l}\text { "process designed to expedite the development and review of drugs that are intended to treat } \\
\text { a serious condition and preliminary clinical evidence indicates that the drug may demonstrate } \\
\text { substantial improvement over available therapy on a clinically significant endpoint(s)"56,57. } \\
\text { Guidance for industry: } \\
\quad \text { Expedited Programs for Serious Conditions - Drugs and Biologics }\end{array}$ \\
\hline $\begin{array}{l}\text { Orphan } \\
\text { designation }\end{array}$ & $\begin{array}{l}\text { Rare disease or condition that affects } 200,000 \text { people or fewer per year in the U.S. }{ }^{59} \\
\text { Guidance for industry: } \\
\text { (Draft) Rare Diseases: Common Issues in Drug Development }{ }^{60}\end{array}$ \\
\hline Biosimilar & $\begin{array}{l}\text { "an abbreviated licensure pathway for biological products that are demonstrated to be } \\
\text { "biosimilar" to or "interchangeable" with an FDA-licensed biological product... a biological } \\
\text { product may be demonstrated to be "biosimilar" if data show that, among other things, the } \\
\text { product is "highly similar" to an already-approved biological product' } 61 \text {. } \\
\text { Guidance for industry: } \\
\text { Quality Considerations in Demonstrating Biosimilarity of a Therapeutic Protein Product to } \\
\text { a Reference Product }{ }^{28} \\
\text { Scientific Considerations in Demonstrating Biosimilarity to a Reference Product }{ }^{27} \\
\text { Biosimilars: Questions and Answers Regarding Implementation of the Biologics Price } \\
\text { Competition and Innovation Act of } 2009^{29} \\
\text { Formal Meetings Between the FDA and Biosimilar Biological Product Sponsors or } \\
\text { Applicants }\end{array}$ \\
\hline
\end{tabular}

Summary of three pathways for the development of novel therapeutics that have emerged or have been finalized since 2011.

\begin{tabular}{|c|c|c|c|c|c|}
\hline$\#$ & $\begin{array}{l}\text { Approval } \\
\text { date }\end{array}$ & $\begin{array}{l}\text { Drug name } \\
\text { (Market name) }\end{array}$ & Class & Description & Use \\
\hline 1 & $11 / 1 / 2013$ & $\begin{array}{l}\text { Obinutuzumab } \\
\text { (Gazyva) }\end{array}$ & $\mathrm{mAb}$ & Humanized anti-CD20 & $\begin{array}{l}\text { Treatment of patients with previously } \\
\text { untreated chronic lymphocytic leukemia } \\
\text { in combination with chlorambucil }\end{array}$ \\
\hline 2 & $9 / 4 / 2014$ & $\begin{array}{l}\text { Pembrolizumab } \\
\text { (Keytruda) }\end{array}$ & $\mathrm{mAb}$ & Humanized anti-PD-1 & $\begin{array}{l}\text { Treatment of patients with unresectable } \\
\text { or metastatic melanoma and disease } \\
\text { progression following ipilimumab and, } \\
\text { if BRAF V600 mutation positive, a BRAF } \\
\text { inhibitor }\end{array}$ \\
\hline 3 & $12 / 3 / 2014$ & $\begin{array}{l}\text { Blinatumomab } \\
\text { (Blincyto) }\end{array}$ & $m A b$ & $\begin{array}{l}\text { Mouse bispecific anti- } \\
\text { CD19/anti-CD3 }\end{array}$ & $\begin{array}{l}\text { Treatment of Philadelphia chromosome- } \\
\text { negative relapsed or refractory B-cell } \\
\text { precursor acute lymphoblastic leukemia } \\
\text { (ALL) }\end{array}$ \\
\hline 4 & $12 / 22 / 2014$ & $\begin{array}{l}\text { Nivolumab } \\
\text { (Opdivo) }\end{array}$ & $\mathrm{mAb}$ & Human anti-PD-1 & $\begin{array}{l}\text { Treatment of unresectable or metastatic } \\
\text { melanoma and disease progression } \\
\text { following ipilimumab and, if BRAF V } 600 \\
\text { mutation positive, a BRAF inhibitor }\end{array}$ \\
\hline 5 & 10/16/2015 & $\begin{array}{l}\text { Idarucizumab } \\
\text { (Praxbind) }\end{array}$ & Fab & $\begin{array}{l}\text { Humanized anti- } \\
\text { dabigatran }\end{array}$ & $\begin{array}{l}\text { Treatment of patients treated with } \\
\text { Pradaxa when reversal of the } \\
\text { anticoagulant effects of dabigatran is } \\
\text { needed for emergency surgery/urgent } \\
\text { procedures and in life-threatening or } \\
\text { uncontrolled bleeding }\end{array}$ \\
\hline 6 & $10 / 23 / 2015$ & $\begin{array}{l}\text { Asfotase-alfa } \\
\text { (Strensiq) }\end{array}$ & $\begin{array}{l}\text { Enzyme/fusion } \\
\text { protein }\end{array}$ & $\begin{array}{l}\text { Tissue non-specific } \\
\text { alkaline phosphatase/Fc } \\
\text { fusion/deca-asparatate } \\
\text { (D10) peptide }\end{array}$ & $\begin{array}{l}\text { Treatment of patients with perinatal/ } \\
\text { infantile- and juvenile-onset } \\
\text { hypophosphatasia }\end{array}$ \\
\hline
\end{tabular}




\begin{tabular}{|c|c|c|c|c|c|}
\hline$\#$ & $\begin{array}{l}\text { Approval } \\
\text { date }\end{array}$ & $\begin{array}{l}\text { Drug name } \\
\text { (Market name) }\end{array}$ & Class & Description & Use \\
\hline 7 & $11 / 16 / 2015$ & $\begin{array}{l}\text { Daratumumab } \\
\text { (Darzalex) }\end{array}$ & mAb & Human anti-CD38 & $\begin{array}{l}\text { Treatment of patients with multiple } \\
\text { myeloma who have received at least } \\
\text { three prior lines of therapy, including } \\
\text { a proteasome inhibitor and an } \\
\text { immunomodulatory agent, or are double- } \\
\text { refractory to a proteasome inhibitor and } \\
\text { an immunomodulatory agent }\end{array}$ \\
\hline 8 & $11 / 30 / 2015$ & $\begin{array}{l}\text { Elotuzumab } \\
\text { (Empliciti) }\end{array}$ & $m A b$ & $\begin{array}{l}\text { Humanized anti- } \\
\text { CD319(SLAMF7) }\end{array}$ & $\begin{array}{l}\text { Treatment of patients with multiple } \\
\text { myeloma who have received one to } \\
\text { three prior therapies }\end{array}$ \\
\hline 9 & $12 / 08 / 2015$ & $\begin{array}{l}\text { Sebelipase alfa } \\
\text { (Kanuma) }\end{array}$ & Enzyme & Lysosomal acid lipase & $\begin{array}{l}\text { Treatment of patients with a diagnosis of } \\
\text { lysosomal acid lipase deficiency }\end{array}$ \\
\hline 10 & $5 / 18 / 2016$ & $\begin{array}{l}\text { Atezolizumab } \\
\text { (Tecentriq) }\end{array}$ & $m A b$ & Humanized anti-PD-L1 & $\begin{array}{l}\text { Treatment of locally advanced or } \\
\text { metastatic urothelial carcinoma who } \\
\text { have disease progression during } \\
\text { or following platinum-containing } \\
\text { chemotherapy or have disease } \\
\text { progression within } 12 \text { months of } \\
\text { neoadjuvant or adjuvant treatment with } \\
\text { platinum-containing chemotherapy }\end{array}$ \\
\hline
\end{tabular}

Comprehensive listing of all FDA-approved therapeutic proteins granted breakthrough therapy designation upon original submission from July 9, 2012, through August 31, 2016, listed in chronological order of FDA approval. In addition, the class of protein, a brief description, and use are included. BRAF, B-Raf proto-oncogene, serine/threonine kinase; CD, cluster of differentiation; Fab, fragment antigen binding; mAb, monoclonal antibody; PD-1, programmed death receptor-1; PD-L1, programmed death-ligand 1; SLAMF7, SLAM family member 7.

Table 5. Therapeutic proteins granted orphan designation upon original submission (2011-2016).

\begin{tabular}{|c|c|c|c|c|c|}
\hline$\#$ & $\begin{array}{l}\text { Approval } \\
\text { date }\end{array}$ & $\begin{array}{l}\text { Drug name } \\
\text { (Market name) }\end{array}$ & Class & Description & Orphan designation \\
\hline 1 & 3/25/2011 & $\begin{array}{l}\text { Ipilimumab } \\
\text { (Yervoy) }\end{array}$ & $m A b$ & Human anti-CTLA-4 & $\begin{array}{l}\text { Treatment of high-risk stage II, stage III, } \\
\text { and stage IV melanoma }\end{array}$ \\
\hline 2 & $6 / 15 / 2011$ & $\begin{array}{l}\text { Belatacept } \\
\text { (Nulojix) }\end{array}$ & Fusion (Fc) & CTLA-4 Fc-fusion & $\begin{array}{l}\text { Prophylaxis of organ rejection in renal } \\
\text { allograft recipients }\end{array}$ \\
\hline 3 & $11 / 18 / 2011$ & $\begin{array}{l}\text { Asparaginase erwinia } \\
\text { chrysanthemi } \\
\text { (Erwinaze) }\end{array}$ & Enzyme & $\begin{array}{l}\text { Asparaginase erwinia } \\
\text { chrysanthemi }\end{array}$ & $\begin{array}{l}\text { Treatment of acute lymphocytic } \\
\text { leukemia }\end{array}$ \\
\hline 4 & $1 / 17 / 2012$ & $\begin{array}{l}\text { Glucarpidase } \\
\text { (Voraxaze) }\end{array}$ & Enzyme & Glucarpidase & $\begin{array}{l}\text { Treatment of patients at risk of } \\
\text { methotrexate toxicity }\end{array}$ \\
\hline 5 & $5 / 1 / 2012$ & $\begin{array}{l}\text { Taliglucerase alfa } \\
\text { (Elelyso) }\end{array}$ & Enzyme & Taliglucerase & Treatment of Gaucher's disease \\
\hline 6 & $12 / 14 / 2012$ & $\begin{array}{l}\text { Raxibacumab } \\
\text { (raxibacumab) }\end{array}$ & mAb & $\begin{array}{l}\text { Human anti-anthrax } \\
\text { protective antigen (PA) }\end{array}$ & Treatment of anthrax \\
\hline 7 & 6/26/2013 & $\begin{array}{l}\text { Coagulation factor IX } \\
\text { recombinant human } \\
\text { (Rixubis) }\end{array}$ & Coagulation factor & Recombinant factor IX & $\begin{array}{l}\text { Prophylactic use to prevent or reduce } \\
\text { the frequency of bleeding episodes } \\
\text { in patients with hemophilia B (routine } \\
\text { prophylaxis in patients where there is no } \\
\text { evidence or suspicion of bleeding) }\end{array}$ \\
\hline 8 & $11 / 1 / 2013$ & $\begin{array}{l}\text { Obinutuzumab } \\
\text { (Gazyva) }\end{array}$ & $m A b$ & Humanized anti-CD20 & $\begin{array}{l}\text { Treatment of chronic lymphocytic } \\
\text { leukemia }\end{array}$ \\
\hline 9 & $12 / 23 / 2013$ & $\begin{array}{l}\text { Coagulation factor } \\
\text { XIII A-subunit } \\
\text { (recombinant) } \\
\text { (Tretten) }\end{array}$ & Coagulation factor & $\begin{array}{l}\text { Recombinant factor XIII } \\
\text { A subunit }\end{array}$ & $\begin{array}{l}\text { Prophylaxis of bleeding associated with } \\
\text { congential factor XIII deficiency }\end{array}$ \\
\hline 10 & 2/14/2014 & $\begin{array}{l}\text { Elosulfase alfa } \\
\text { (Vimizim) }\end{array}$ & Enzyme & Elosulfase alfa & $\begin{array}{l}\text { Treatment of mucopolysaccharidosis } \\
\text { type IV A (Morquio A syndrome) }\end{array}$ \\
\hline 11 & 2/24/2014 & $\begin{array}{l}\text { Metreleptin } \\
\text { (Myalept) }\end{array}$ & Hormone & Metreleptin & $\begin{array}{l}\text { Treatment of metabolic disorders } \\
\text { secondary to lipodystrophy }\end{array}$ \\
\hline 12 & $3 / 28 / 2014$ & $\begin{array}{l}\text { Coagulation factor IX } \\
\text { (recombinant), } \\
\text { Fc fusion protein } \\
\text { (Alprolix) }\end{array}$ & Coagulation factor & $\begin{array}{l}\text { Recombinant factor IX } \\
\text { Fc fusion }\end{array}$ & $\begin{array}{l}\text { Control and prevention of hemorrhagic } \\
\text { episodes in patients with hemophilia } \\
\text { B (congenital factor IX deficiency or } \\
\text { Christmas disease) }\end{array}$ \\
\hline
\end{tabular}




\begin{tabular}{|c|c|c|c|c|c|}
\hline$\#$ & $\begin{array}{l}\text { Approval } \\
\text { date }\end{array}$ & $\begin{array}{l}\text { Drug name } \\
\text { (Market name) }\end{array}$ & Class & Description & Orphan designation \\
\hline 13 & $4 / 21 / 2014$ & $\begin{array}{l}\text { Ramucirumab } \\
\text { (Cyramza) }\end{array}$ & $\mathrm{mAb}$ & $\begin{array}{l}\text { Human anti-VEGFR2 } \\
\text { (KDR) }\end{array}$ & Treatment of gastric cancer \\
\hline 14 & $4 / 23 / 2014$ & Siltuximab (Sylvant) & $\mathrm{mAb}$ & $\begin{array}{l}\text { Mouse/human chimeric } \\
\text { anti-IL-6 }\end{array}$ & Treatment of Castleman's disease \\
\hline 15 & $4 / 23 / 2014$ & $\begin{array}{l}\text { Pembrolizumab } \\
\text { (Keytruda) }\end{array}$ & mAb & Humanized anti-PD-1 & $\begin{array}{l}\text { Treatment of stage IIB through IV } \\
\text { malignant melanoma }\end{array}$ \\
\hline 16 & 6/6/2014 & $\begin{array}{l}\text { Antihemophilic } \\
\text { factor (recombinant), } \\
\text { Fc fusion protein } \\
\text { (Eloctate) }\end{array}$ & Coagulation factor & $\begin{array}{l}\text { Recombinant factor VIII } \\
\text { Fc-fusion }\end{array}$ & Treatment of hemophilia A \\
\hline 17 & $7 / 16 / 2014$ & $\begin{array}{l}\text { C1 esterase inhibitor } \\
\text { recombinant } \\
\text { (Ruconest) }\end{array}$ & Plasma protein & $\begin{array}{l}\text { Recombinant C1 } \\
\text { esterase inhibitor }\end{array}$ & $\begin{array}{l}\text { Treatment of (acute attacks of) } \\
\text { angioedema caused by hereditary } \\
\text { or acquired C1-esterase inhibitor } \\
\text { deficiency }\end{array}$ \\
\hline 18 & $10 / 23 / 2014$ & $\begin{array}{l}\text { Antihemophilic factor } \\
\text { porcine, } \\
\text { B-domain truncated } \\
\text { recombinant } \\
\text { (Obizur) }\end{array}$ & Coagulation factor & $\begin{array}{l}\text { Recombinant factor VIII } \\
\text { (porcine) }\end{array}$ & $\begin{array}{l}\text { Treatment and prevention of episodic } \\
\text { bleeding in patients with inhibitor } \\
\text { antibodies to human coagulation } \\
\text { factor VIII }\end{array}$ \\
\hline 19 & $12 / 3 / 2014$ & $\begin{array}{l}\text { Blinatumomab } \\
\text { (Blincyto) }\end{array}$ & mAb & $\begin{array}{l}\text { Mouse bispecific anti- } \\
\text { CD19/anti-CD3 }\end{array}$ & $\begin{array}{l}\text { Treatment of acute lymphocytic } \\
\text { leukemia }\end{array}$ \\
\hline 20 & $12 / 22 / 2014$ & $\begin{array}{l}\text { Nivolumab } \\
\text { (Opdivo) }\end{array}$ & mAb & Human anti-PD-1 & Treatment of stage IIb to IV melanoma \\
\hline 21 & $1 / 23 / 2015$ & $\begin{array}{l}\text { Parathyroid hormone } \\
\text { (Natpara) }\end{array}$ & Hormone & Parathyroid hormone & Treatment of hypoparathyroidism \\
\hline 22 & $3 / 10 / 2015$ & $\begin{array}{l}\text { Dinutuximab } \\
\text { (Unituxin) }\end{array}$ & $\mathrm{mAb}$ & $\begin{array}{l}\text { Mouse/human chimeric } \\
\text { anti-GD2 }\end{array}$ & Treatment of neuroblastoma \\
\hline 23 & $8 / 27 / 2015$ & $\begin{array}{l}\text { Evolocumab } \\
\text { (Repatha) }\end{array}$ & mAb & $\begin{array}{l}\text { Human anti-proprotein } \\
\text { convertase substilisin/ } \\
\text { kexin type } 9 \text { (PCSK9) }\end{array}$ & $\begin{array}{l}\text { Treatment of homozygous familial } \\
\text { hypercholesterolemia }\end{array}$ \\
\hline 24 & $10 / 16 / 2015$ & $\begin{array}{l}\text { Idarucizumab } \\
\text { (Praxbind) }\end{array}$ & $\mathrm{Fab}$ & $\begin{array}{l}\text { Humanized anti- } \\
\text { dabigatran }\end{array}$ & $\begin{array}{l}\text { To reverse the anticoagulant effect of } \\
\text { dabigatran due to uncontrolled life- } \\
\text { threatening bleeding requiring urgent } \\
\text { intervention or a need to undergo an } \\
\text { emergency surgery/urgent invasive } \\
\text { procedure }\end{array}$ \\
\hline 25 & $10 / 23 / 2015$ & $\begin{array}{l}\text { Asfotase-alfa } \\
\text { (Strensiq) }\end{array}$ & $\begin{array}{l}\text { Enzyme/fusion } \\
\text { protein }\end{array}$ & $\begin{array}{l}\text { Tissue non-specific } \\
\text { alkaline phosphatase/ } \\
\text { Fc fusion/deca- } \\
\text { asparatate (D10) } \\
\text { peptide }\end{array}$ & Treatment of hypophosphatasia \\
\hline 26 & $11 / 16 / 2015$ & $\begin{array}{l}\text { Daratumumab } \\
\text { (Darzalex) }\end{array}$ & $\mathrm{mAb}$ & Human anti-CD38 & Treatment of multiple myeloma \\
\hline 27 & $11 / 24 / 2015$ & $\begin{array}{l}\text { Necitumumab } \\
\text { (Portrazza) }\end{array}$ & mAb & $\begin{array}{l}\text { Human anti-epidermal } \\
\text { growth factor receptor }\end{array}$ & $\begin{array}{l}\text { Treatment of squamous non-small cell } \\
\text { lung cancer }\end{array}$ \\
\hline 28 & $12 / 8 / 2015$ & $\begin{array}{l}\text { Sebelipase alfa } \\
\text { (Kanuma) }\end{array}$ & Enzyme & Lysosomal acid lipase & $\begin{array}{l}\text { Treatment of lysosomal acid lipase } \\
\text { deficiency }\end{array}$ \\
\hline 29 & $12 / 8 / 2015$ & $\begin{array}{l}\text { von Willebrand Factor } \\
\text { (Recombinant) } \\
\text { (Vonvendi) }\end{array}$ & Plasma protein & $\begin{array}{l}\text { Recombinant von } \\
\text { Willebrand Factor }\end{array}$ & Treatment of von Willebrand disease \\
\hline 30 & $3 / 4 / 2016$ & $\begin{array}{l}\text { Coagulation factor IX } \\
\text { recombinant human } \\
\text { (Idelvion) }\end{array}$ & Coagulation factor & $\begin{array}{l}\text { Recombinant factor IX } \\
\text { albumin fusion }\end{array}$ & $\begin{array}{l}\text { Treatment of patients with congenital } \\
\text { factor IX deficiency (hemophilia B) }\end{array}$ \\
\hline 31 & 3/18/2016 & $\begin{array}{l}\text { Obiltoxaximab } \\
\text { (Anthim) }\end{array}$ & mAb & $\begin{array}{l}\text { Mouse/human chimeric } \\
\text { anti-Bacillus anthracis }\end{array}$ & $\begin{array}{l}\text { Treatment of exposure to } B \text {. anthracis } \\
\text { spores }\end{array}$ \\
\hline
\end{tabular}


manufacture. Typically, the developer of a biosimilar has to retrieve the reference protein as a finished drug product, purify the drug substance, and reverse-engineer the process. Consequently, the FDA biosimilar framework does not require an identical manufacturing process for the innovator product and the biosimilar. Therefore, it is not expected that, in the demonstration of biosimilarity, quality attributes such as protein structure and posttranslational modifications measured in comparative physiochemical and functional studies will be identical between the biosimilar and reference product, but highly similar. It has, on the contrary, been argued that deviations from the technology of the innovator may actually be desirable ${ }^{9,34}$. This is because since the introduction of the first recombinant DNA-derived therapeutic proteins, the technology to produce and purify these products has greatly improved. An increased focus upon innovation and streamlining of upstream and downstream processing has been reported by the widely respected "Biopharmaceutical benchmarks" series s, $^{3,35}$. Thus, it is not necessary for manufacturers of biosimilars to be locked into the obsolete technologies of the manufacturers of the original products for whom changing methods have major financial and regulatory consequences. With this in mind, it seems much more desirable for biosimilars to be produced and analyzed by the best technology on offer.

\section{Emerging trends, challenges, and opportunities}

As protein-engineering technologies and regulatory frameworks evolve over time, so do protein therapeutics. Optimized versions of existing therapies can be achieved through better drug targeting as well as enhancing potency and functionality. By understanding the mechanism of action as well as the structure-function relationship of a protein, rational design and engineering strategies allow the modification of its activity or the introduction of new activities, leading to customization of existing proteins or the generation of novel therapeutics for specific clinical applications. Here, we will highlight just two examples of rational modifications to existing protein drugs achieved through protein engineering that have led to the approval of novel second-generation therapeutics (see Box 1 and Box 2).

\section{Box 1. Engineering a second-generation cytotoxic T lymphocyte-associated protein 4 (CTLA4)-Fc fusion}

Abatacept, a CTLA4-Fc fusion protein therapeutic, was developed by Bristol-Myers Squibb and approved by the U.S. Food and Drug Administration (FDA) in December 2005 as the first selective modulator of co-stimulation for the treatment of rheumatoid arthritis $^{62}$. CTLA4-Fc competitively inhibits CD28 on the surface of $T$ cells for binding to the $\mathrm{B} 7$ family co-stimulatory receptors CD80 (B7-1) and CD86 (B7-2) expressed on the surface of antigenpresenting cells. Although this $\mathrm{F}$-fusion has been shown to be efficacious in the treatment of rheumatoid arthritis, abatacept was not as effective when tested pre-clinically in non-human primate transplant models ${ }^{63,64}$. Experimental data suggested that abatacept did not completely block B7 co-stimulatory receptormediated T-cell activation; therefore, a similar molecule with enhanced affinity for CD80/CD86 could be of therapeutic benefit as an immunosuppressant to prevent organ transplant rejection. Belatacept, formerly known as LEA29Y, was therefore developed by Bristol-Myers Squibb as a second-generation CTLA4-Fc. Two amino acid substitutions in the CTLA-4 ligand-binding region (L104E and A29Y) resulted in enhanced in vitro binding to CD80 (about two fold more avidly) and CD86 (about four fold more avidly) in addition to greater immunosuppression of T-cell activation in vitro (about 10-fold) as compared with the parent molecule (abatacept) ${ }^{65}$. Belatacept's enhanced activity was also observed in vivo with prolonged renal allograft survival in non-human primates (rhesus monkeys) compared with abatacept ${ }^{33,65}$. In clinical studies of kidney allograft recipients, belatacept was shown to be associated with similar levels of patient and graft survival but superior renal function and reduced renal and non-renal toxicities compared with cyclosporine at 12 months after transplant ${ }^{66}$ The rationally designed analog with enhanced CD80 and CD86 binding, belatacept, a second-generation selective co-stimulation blocker, was approved by the FDA on June 15, 2011, for the prophylaxis of kidney transplant rejection ${ }^{67}$.

Box 2. Engineering a second-generation anti-CD20 monoclonal antibody $(\mathrm{mAb})$

Rituximab, a chimeric mouse/human type I anti-CD20 mAb, was developed by Genentech and approved by the U.S. Food and Drug Administration (FDA) in November 1997 for the treatment of B-cell non-Hodgkin's lymphoma. Rituximab binds to CD20 expressed on the surface of many B cells (but not plasma cells), resulting in $\mathrm{B}$-cell depletion via antibody-dependent cellular cytotoxicity (ADCC), complement-mediated cytotoxicity (CMA), and the induction of direct cell death (apoptosis) ${ }^{68,69}$. Both ADCC and $\mathrm{CMA}$ are dependent upon the $\mathrm{Fc}_{\mathrm{C}}$ region of the mAb interacting with $\mathrm{FC}_{\mathrm{C}}$ gamma receptor IIIA (FcyRIIIA) or complement component $1 \mathrm{q}(\mathrm{C} 1 \mathrm{q})$, respectively. In the case of ADCC, antibody-bound CD20+ $\mathrm{B}$ cells are targeted for cellular depletion by FcyRIIIAexpressing monocytes, macrophages, and natural killer cells. Given the importance of FcyRIIIA engagement and signaling in the mechanism of B-cell depletion, specifically engineering a next-generation $\mathrm{mAb} \mathrm{b}^{70-72}$ with enhanced functional activity would be of clinical benefit. Gazyva, formerly known as GA101, a type II anti-CD20 mAb, was engineered and developed by Genentech. This second-generation medicine contains a CD20-binding variable region introduced through protein engineering to take advantage of the potent induction of direct cell death and limited C1q binding typical of type II anti-CD20 antibodies ${ }^{51}$. The Fc region of this $\mathrm{mAb}$ has also been glyco-engineered by producing the protein drug in an expression cell line that overexpresses the glycosylation enzymes $\beta 1,4-N$-acetylglucosaminyltransferase III (GnTIII) and Golgi $\alpha$-mannosidase II (ManII) ${ }^{73}$, thereby enriching for afucosylated oligosaccharides. Changes to the Fc glycosylation at Asn297 can lead to changes in FcyR binding, phagocytosis, and cytotoxicity ${ }^{74}$. In fact, afucosylated antibodies have higher-affinity FcyRIIIA binding and enhanced ADCC activity compared with parent fucosylated counterparts ${ }^{20,75}$. The effects of these proteinengineering strategies can be observed in pre-clinical studies as Gazyva demonstrated higher affinity to FcyRIIIA by SPR and induced more potent ADCC when compared with rituximab ${ }^{51}$ These significant improvements were also observed in phase 3 clinical studies as patients with $\mathrm{CD} 2 \mathrm{O}^{+}$chronic lymphocytic leukemia treated with Gazyva with chlorambucil had prolonged median progression-free survival time (26.7 months) when compared with patients treated with rituximab with chlorambucil

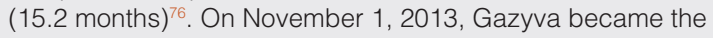
first glyco-engineered $m A b$ drug to be approved by the FDA. This second-generation anti-CD20 mAb for treatment of chronic lymphocytic leukemia was also the first therapeutic protein to receive breakthrough therapy designation. In addition, Gazyva was granted orphan designation upon approval and contains pharmacogenetics information included on the drug label. 
Over this examination of the recently approved therapeutic protein drug landscape, several emerging trends have become apparent. We anticipate that the inclusion of pharmacogenetics information in drug labeling and the importance of "companion diagnostics" will become the focus of increased attention. The FDA has been encouraging drug developers to collect and submit pharmacogenomics data through a guidance, "Pharmacogenomic Data Submissions", issued in March 2005 ${ }^{36}$. Pharmacogenetics can play an important role in identifying responders and non-responders to medications, avoiding adverse events, and optimizing drug dose. Drug labeling may contain information on genomic biomarkers and can describe drug exposure and clinical response variability, risk for adverse events, genotype-specific dosing, mechanisms of drug action, and polymorphic drug target and disposition genes. Therefore, pharmacogenetic profiling is of particular importance when potential drug candidates exhibit highly variable safety, efficacy, or pharmacokinetics profiles. In January 2013, the FDA issued a guidance, titled
"Clinical Pharmacogenomics: Premarket Evaluation in Early-Phase Clinical Studies and Recommendations for Labeling", to assist drug developers with conducting exploratory pharmacogenomic investigations, enrichment strategies for clinical trials, adaptive trial designs, or companion diagnostics ${ }^{37}$. Pharmacogenetic information and changes in drug labeling can lead to drugs targeted for different populations, personalized dosing regimens, and companion diagnostics. There have been 11 therapeutic proteins approved since 2011 that have included pharmacogenetic biomarkers in their drug labels (Table 6). For a complete listing of drugs with available pharmacogenetics information, see the FDA's Table of Pharmacogenomic Biomarkers in Drug Labeling ${ }^{38}$. The FDA's review process will continue to adapt as the incorporation of pharmacogenetic information becomes more commonplace. This will also require a coordinated cross-center review to incorporate the companion diagnostic/sequencing in the drug development/ licensure process.

\section{Table 6. Therapeutic proteins with pharmacogenetic biomarkers in drug labeling.}

\begin{tabular}{|c|c|c|c|c|c|c|}
\hline$\#$ & $\begin{array}{l}\text { Approval } \\
\text { date }\end{array}$ & $\begin{array}{l}\text { Drug name } \\
\text { (Market name) }\end{array}$ & Class & Description & $\begin{array}{l}\text { Pharmacogenetic } \\
\text { biomarker }\end{array}$ & Therapeutic area \\
\hline 1 & 6/8/2012 & $\begin{array}{l}\text { Pertuzumab } \\
\text { (Perjeta) }\end{array}$ & mAb & $\begin{array}{l}\text { Humanized anti- } \\
\text { human epidermal } \\
\text { growth factor } \\
\text { receptor } 2 \text { (HER2) }\end{array}$ & $\begin{array}{l}\text { HER2 protein } \\
\text { overexpression positive }\end{array}$ & Oncology \\
\hline 2 & 2/22/2013 & $\begin{array}{l}\text { Ado-trastuzumab } \\
\text { emtansine (Kadcyla) }\end{array}$ & $\begin{array}{l}\text { Antibody- } \\
\text { drug } \\
\text { conjugate }\end{array}$ & $\begin{array}{l}\text { Humanized } \\
\text { anti-HER2/neu } \\
\text { conjugated to } \\
\text { emtansine }\end{array}$ & $\begin{array}{l}\text { HER2 protein } \\
\text { overexpression or gene } \\
\text { amplification positive }\end{array}$ & Oncology \\
\hline 3 & $11 / 1 / 2013$ & $\begin{array}{l}\text { Obinutuzumab } \\
\text { (Gazyva) }\end{array}$ & $\mathrm{mAb}$ & $\begin{array}{l}\text { Humanized } \\
\text { anti-CD20 }\end{array}$ & CD20 antigen positive & Oncology \\
\hline 4 & 2/14/2014 & $\begin{array}{l}\text { Elosulfase alfa } \\
\text { (Vimizim) }\end{array}$ & Enzyme & Elosulfase alfa & $\begin{array}{l}\mathrm{N} \text {-acetylgalactosamine-6- } \\
\text { sulfatase deficient }\end{array}$ & $\begin{array}{l}\text { Inborn errors of } \\
\text { metabolism }\end{array}$ \\
\hline 5 & $9 / 4 / 2014$ & $\begin{array}{l}\text { Pembrolizumab } \\
\text { (Keytruda) }\end{array}$ & mAb & Humanized anti-PD-1 & $\begin{array}{l}\text { (1) BRAF V600 mutation } \\
\text { positive, (2) PD-L1 protein } \\
\text { expression positive }\end{array}$ & Oncology \\
\hline 6 & $12 / 3 / 2014$ & $\begin{array}{l}\text { Blinatumomab } \\
\text { (Blincyto) }\end{array}$ & mAb & $\begin{array}{l}\text { Mouse bispecific } \\
\text { anti-CD19/anti-CD3 }\end{array}$ & $\begin{array}{l}\text { Philadelphia chromosome } \\
\text { negative }\end{array}$ & Oncology \\
\hline 7 & 12/22/2014 & $\begin{array}{l}\text { Nivolumab } \\
\text { (Opdivo) }\end{array}$ & mAb & Human anti-PD-1 & $\begin{array}{l}\text { (1) BRAF V600 mutation } \\
\text { positive, (2) PD-L1 protein } \\
\text { expression positive }\end{array}$ & Oncology \\
\hline 8 & $1 / 23 / 2015$ & $\begin{array}{l}\text { Parathyroid } \\
\text { hormone } \\
\text { (Natpara) }\end{array}$ & Hormone & Parathyroid hormone & $\begin{array}{l}\text { Calcium sensing receptor } \\
\text { mutation positive }\end{array}$ & $\begin{array}{l}\text { Inborn errors of } \\
\text { metabolism }\end{array}$ \\
\hline 9 & 3/10/2015 & $\begin{array}{l}\text { Dinutuximab } \\
\text { (Unituxin) }\end{array}$ & $m A b$ & $\begin{array}{l}\text { Mouse/human } \\
\text { chimeric anti-GD2 }\end{array}$ & MYCN amplification positive & Oncology \\
\hline 10 & $7 / 24 / 2015$ & $\begin{array}{l}\text { Alirocumab } \\
\text { (Praluent) }\end{array}$ & $\mathrm{mAb}$ & $\begin{array}{l}\text { Human anti- } \\
\text { proprotein convertase } \\
\text { substilisin/kexin } \\
\text { type } 9 \text { (PCSK9) }\end{array}$ & $\begin{array}{l}\text { LDL receptor mutation } \\
\text { heterozygotes }\end{array}$ & Endocrinology \\
\hline 11 & $8 / 27 / 2015$ & $\begin{array}{l}\text { Evolocumab } \\
\text { (Repatha) }\end{array}$ & $\mathrm{mAb}$ & $\begin{array}{l}\text { Human anti- } \\
\text { proprotein convertase } \\
\text { substilisin/kexin } \\
\text { type } 9 \text { (PCSK9) }\end{array}$ & $\begin{array}{l}\text { LDL receptor mutation } \\
\text { heterozygotes and } \\
\text { homozygotes }\end{array}$ & Endocrinology \\
\hline
\end{tabular}

Comprehensive listing of all FDA-approved therapeutic proteins with pharmacogenetics biomarkers in drug labeling from January 1 , 2011 , through August 31, 2016, listed in chronological order of FDA approval. In addition, the class of protein, a brief description, pharmacogenetics biomarker, and therapeutic area are included. BRAF, B-Raf proto-oncogene, serine/threonine kinase; CD, cluster of differentiation; GD2, disialoganglioside; LDL, low-density lipoprotein; mAb, monoclonal antibody; MYCN, v-myc avian myelocytomatosis viral oncogene neuroblastoma derived homolog; PD-1, programmed death receptor-1; PD-L1, programmed death-ligand 1. 
It is reasonable to anticipate that proteins will be more extensively engineered in the future. This means that the new generation of therapeutic proteins will carry neo-sequences not found in nature. Thus, the potential risks of immunogenicity (undesirable immune responses to therapeutic proteins) ${ }^{39}$ will also increase and, in turn, demand new technologies for immunogenicity risk assessment and mitigation ${ }^{39,40}$. Protein engineering is no longer restricted to altering the primary sequence of proteins. On the other hand, the rapidly growing trend of codon optimization involves the substitution of synonymous codons to improve protein synthesis and increase protein production ${ }^{41,42}$. A growing scientific literature suggests that although synonymous codons do not alter protein sequence they can have profound effects on protein folding and function ${ }^{43-45}$. Consequently, these therapeutic proteins designed by using such strategies will have to be carefully evaluated.
Finally, a confluence of computational and high-throughput experimental methods for protein-engineering and "off the shelf" platform technologies has ushered in unprecedented opportunities to develop safe, effective, and more convenient protein therapeutics. These opportunities do come with risks but rapid advances in new technologies as well as the underlying science suggest that these risks can be managed.

\section{Competing interests}

The authors declare that they have no competing interests.

\section{Grant information}

The author(s) declared that no grants were involved in supporting this work.
1. Kimchi-Sarfaty $\mathrm{C}$, Schiller $\mathrm{T}$, Hamasaki-Katagiri N, et al.: Building better drugs: developing and regulating engineered therapeutic proteins. Trends Pharmacol Sci. 2013; 34(10): 534-48.

PubMed Abstract | Publisher Full Text

2. Carter PJ: Introduction to current and future protein therapeutics: a protein engineering perspective. Exp Cell Res. 2011; 317(9): 1261-9.

PubMed Abstract | Publisher Full Text

3. Walsh G: Biopharmaceutical benchmarks 2014. Nat Biotechnol. 2014; 32(10): 992-1000.

PubMed Abstract | Publisher Full Text

4. Schellekens $\mathrm{H}$ : Biosimilar therapeutics-what do we need to consider? NDT Plus. 2009; 2(Suppl_1): i27-i36.

PubMed Abstract | Publisher Full Text | Free Full Text

5. Bandaranayake AD, Almo SC: Recent advances in mammalian protein production. FEBS Lett. 2014; 588(2): 253-60.

PubMed Abstract | Publisher Full Text | Free Full Text

6. Butler M, Meneses-Acosta A: Recent advances in technology supporting biopharmaceutical production from mammalian cells. Appl Microbiol Biotechnol. 2012; 96(4): 885-94.

PubMed Abstract | Publisher Full Text

7. Zhu J: Mammalian cell protein expression for biopharmaceutical production. Biotechnol Adv. 2012; 30(5): 1158-70. PubMed Abstract | Publisher Full Text

8. F Cipriano D, Burnham M, Hughes JV: Effectiveness of various processing steps for viral clearance of therapeutic proteins: database analyses of commonly used steps. Methods Mol Biol. 2012; 899: 277-92. PubMed Abstract | Publisher Full Text | F1000 Recommendation

9. Chirino AJ, Mire-Sluis A: Characterizing biological products and assessing comparability following manufacturing changes. Nat Biotechnol. 2004; 22(11): 1383-91.

PubMed Abstract | Publisher Full Text

10. Tobin $\mathrm{PH}$, Richards $\mathrm{DH}$, Callender RA, et al:: Protein engineering: a new frontie for biological therapeutics. Curr Drug Metab. 2014; 15(7): 743-56. PubMed Abstract | Publisher Full Text | Free Full Text

11. Wurm FM: Production of recombinant protein therapeutics in cultivated mammalian cells. Nat Biotechnol. 2004; 22(11): 1393-8. PubMed Abstract | Publisher Full Text

12. Lutz S: Beyond directed evolution--semi-rational protein engineering and design. Curr Opin Biotechnol. 2010; 21(6): 734-43. PubMed Abstract | Publisher Full Text | Free Full Text

13. Levin D, Golding B, Strome SE, et al.: Fc fusion as a platform technology: potential for modulating immunogenicity. Trends Biotechnol. 2015; 33(1): 27-34. PubMed Abstract | Publisher Full Text

14. Rath T, Baker K, Dumont JA, et al.: Fc-fusion proteins and FcRn: structural insights for longer-lasting and more effective therapeutics. Crit Rev Biotechnol. 2015; 35(2): 235-54.

PubMed Abstract | Publisher Full Text | Free Full Text

15. F Andersen JT, Pehrson R, Tolmachev V, et al:: Extending half-life by indirect targeting of the neonatal $\mathrm{Fc}$ receptor (FcRn) using a minimal albumin binding domain. J Biol Chem. 2011; 286(7): 5234-41.

PubMed Abstract | Publisher Full Text | Free Full Text | F1000 Recommendation

16. Turecek PL, Bossard MJ, Schoetens F, et al:: PEGylation of Biopharmaceuticals: A Review of Chemistry and Nonclinical Safety Information of Approved Drugs. J Pharm Sci. 2016; 105(2): 460-75.

PubMed Abstract | Publisher Full Text

17. Strohl WR: Fusion Proteins for Half-Life Extension of Biologics as a Strategy to Make Biobetters. BioDrugs. 2015; 29(4): 215-39.

PubMed Abstract | Publisher Full Text | Free Full Text

18. Coppola A, Di Capua M, De Simone C: Primary prophylaxis in children with haemophilia. Blood Transfus. 2008; 6(Suppl 2): s4-11.

PubMed Abstract | Free Full Text

19. Casi G, Neri D: Antibody-drug conjugates: basic concepts, examples and future perspectives. J Control Release. 2012; 161(2): 422-8. PubMed Abstract | Publisher Full Text

20. Jefferis R: Glycosylation as a strategy to improve antibody-based therapeutics. Nat Rev Drug Discov. 2009; 8(8): 226-34. PubMed Abstract | Publisher Full Text

21. Costa AR, Rodrigues ME, Henriques M, et al.: Glycosylation: impact, control and improvement during therapeutic protein production. Crit Rev Biotechnol. 2014; 34(4): 281-99.

PubMed Abstract | Publisher Full Text

22. Food and Drug Administration: Purple Book: Lists of Licensed Biological Products with Reference Product Exclusivity and Biosimilarity or Interchangeability Evaluations. 2016; 2016.

Reference Source

23. Food and Drug Administration: Fact Sheet: Breakthrough Therapies. 2016; 2016. Reference Source

24. Schieppati A, Henter JI, Daina E, et al:: Why rare diseases are an important medical and social issue. Lancet. 2008; 371(9629): 2039-41. PubMed Abstract | Publisher Full Text

25. Food and Drug Administration: Orphan Drug Regulations: Regulatory History. $2015 ; 2016$.

Reference Source

26. Roger SD: Biosimilars: current status and future directions. Expert Opin Biol Ther. 2010; 10(7): 1011-8. PubMed Abstract | Publisher Full Text

27. Food and Drug Administration: Scientific Considerations in Demonstrating Biosimilarity to a Reference Product (Guidance for Industry). 2015; 2016. Reference Source

28. Food and Drug Administration: Quality Considerations in Demonstrating Biosimilarity of a Therapeutic Protein Product to a Reference Product (Guidance for Industry). 2015; 2016 Reference Source

29. Food and Drug Administration: Biosimilars: Questions and Answers Regarding Implementation of the Biologics Price Competition and Innovation Act of 2009 (Guidance for Industry). 2015; 2016. Reference Source

30. Food and Drug Administration: Formal Meetings Between the FDA and 
Biosimilar Biological Product Sponsors or Applicants (Guidance for Industry). 2015; 2016.

Reference Source

31. Food and Drug Administration: FDA approves first biosimilar product Zarxio. 2015; 2016.

Reference Source

32. Food and Drug Administration: FDA approves Inflectra, a biosimilar to Remicade. 2016; 2016.

Reference Source

33. Food and Drug Administration: FDA approves Erelzi, a biosimilar to Enbrel. 2016; 2016.

Reference Source

34. Schellekens H, Moors E: Clinical comparability and European biosimilar regulations. Nat Biotechnol. 2010; 28(1): 28-31.

PubMed Abstract | Publisher Full Text

35. Walsh G: Biopharmaceutical benchmarks 2010. Nat Biotechnol. 2010; 28(9): 917-24.

PubMed Abstract | Publisher Full Text

36. Food and Drug Administration: Guidance for Industry: Pharmacogenomic Data Submissions. 2005; 2016.

Reference Source

37. Food and Drug Administration: Guidance for Industry: Clinical Pharmacogenomics: Premarket Evaluation in Early-Phase Clinical Studies and Recommendations for Labeling. 2013; 2016.

Reference Source

38. Food and Drug Administration: Table of Pharmacogenomic Biomarkers in Drug Labeling. 2016; 2016.

Reference Source

39. Shankar G, Pendley C, Stein KE: A risk-based bioanalytical strategy for the assessment of antibody immune responses against biological drugs. $\mathrm{Nat}$ Biotechnol. 2007; 25(5): 555-61.

PubMed Abstract | Publisher Full Text

40. F Yin L, Chen X, Vicini P, et al:: Therapeutic outcomes, assessments, risk factors and mitigation efforts of immunogenicity of therapeutic protein products. Cell Immunol. 2015; 295(2): 118-26. PubMed Abstract | Publisher Full Text | F1000 Recommendation

41. Maertens B, Spriestersbach A, von Groll U, et al:: Gene optimization mechanisms: a multi-gene study reveals a high success rate of full-length human proteins expressed in Escherichia coli. Protein Sci. 2010; 19(7): 1312-26. PubMed Abstract | Publisher Full Text | Free Full Text

42. F Mauro VP, Chappell SA: A critical analysis of codon optimization in human therapeutics. Trends Mol Med. 2014; 20(11): 604-13.

PubMed Abstract | Publisher Full Text | Free Full Text | F1000 Recommendation

43. Hunt R, Sauna ZE, Ambudkar SV, et al:: Silent (synonymous) SNPs: should we care about them? Methods Mol Biol. 2009; 578: 23-39.

PubMed Abstract | Publisher Full Text

44. Tsai C, Sauna ZE, Kimchi-Sarfaty C, et al:: Synonymous mutations and ribosome stalling can lead to altered folding pathways and distinct minima. $J \mathrm{Mol} B \mathrm{BiO}$. 2008; 383(2): 281-91.

PubMed Abstract | Publisher Full Text | Free Full Text

45. Sauna ZE, Kimchi-Sarfaty C: Understanding the contribution of synonymous mutations to human disease. Nat Rev Genet. 2011; 12(10): 683-91. PubMed Abstract | Publisher Full Text

46. Houdebine LM: Production of pharmaceutical proteins by transgenic animals. Comp Immunol Microbiol Infect Dis. 2009; 32(2): 107-21. PubMed Abstract | Publisher Full Text

47. $\mathrm{F}$ van Veen HA, Koiter J, Vogelezang CJ, et al.: Characterization of recombinant human $\mathrm{C} 1$ inhibitor secreted in milk of transgenic rabbits J Biotechnol. 2012; 162(2-3): 319-26.

PubMed Abstract | Publisher Full Text | F1000 Recommendation

48. Hellwig S, Drossard J, Twyman RM, et al:: Plant cell cultures for the production of recombinant proteins. Nat Biotechnol. 2004; 22(11): 1415-22. PubMed Abstract | Publisher Full Text

49. Grabowski GA, Golembo M, Shaaltiel Y: Taliglucerase alfa: an enzyme replacement therapy using plant cell expression technology. Mol Genet Metab. 2014; 112(1): 1-8.

PubMed Abstract | Publisher Full Text

50. Fox JL: First plant-made biologic approved. Nat Biotech. 2012; 30(6): 472.

51. F Mössner E, Brünker $P$, Moser S, et al.: Increasing the efficacy of CD20 antibody therapy through the engineering of a new type II anti-CD20 antibody with enhanced direct and immune effector cell-mediated B-cell cytotoxicity. Blood 2010; 115(22): 4393-402.

PubMed Abstract | Publisher Full Text | Free Full Text | F1000 Recommendation

52. Peters RT, Low SC, Kamphaus GD, et al:: Prolonged activity of factor IX as a monomeric Fc fusion protein. Blood. 2010; 115(10): 2057-64. PubMed Abstract | Publisher Full Text

53. F Dumont JA, Liu T, Low SC, et al.: Prolonged activity of a recombinant factor VIII-Fc fusion protein in hemophilia A mice and dogs. Blood. 2012; 119(13): $3024-30$.

PubMed Abstract | Publisher Full Text | Free Full Text | F1000 Recommendation
54. F Powell JS, Josephson NC, Quon D, et al:: Safety and prolonged activity of recombinant factor VIII Fc fusion protein in hemophilia A patients. Blood 2012; 119(13): 3031-7

PubMed Abstract | Publisher Full Text | Free Full Text | F1000 Recommendation

55. F Pelegri-O'Day EM, Lin EW, Maynard HD: Therapeutic protein-polymer conjugates: advancing beyond PEGylation. J Am Chem Soc. 2014; 136(41): 14323-32.

PubMed Abstract | Publisher Full Text | F1000 Recommendation

56. Food and Drug Administration: Breakthrough Therapy. 2014; 2016. Reference Source

57. Food and Drug Administration: Fact Sheet: Breakthrough Therapies. 2014; 2016 Reference Sourc

58. Food and Drug Administration: Guidance for Industry Expedited Programs for Serious Conditions - Drugs and Biologics. 2014; 2016 Reference Source

59. Food and Drug Administration: Designating an Orphan Product: Drugs and Biological Products. 2016; 2016. Reference Source

60. Food and Drug Administration: Rare Diseases: Common Issues in Drug Development (Guidance for Industry- Draft). 2015; 2016. Reference Source

61. Food and Drug Administration: Information on Biosimilars. 2016; 2016 Reference Source

62. Moreland L, Bate G, Kirkpatrick P: Abatacept. Nat Rev Drug Discov. 2006; 5(3): 185-6.

PubMed Abstract | Publisher Full Text

63. Kirk AD, Harlan DM, Armstrong NN, et al.: CTLA4-Ig and anti-CD40 ligand prevent renal allograft rejection in primates. Proc Natl Acad Sci U S A. 1997; 94(16): 8789-94.

PubMed Abstract | Publisher Full Text | Free Full Text

64. Levisetti MG, Padrid PA, Szot GL, et al: Immunosuppressive effects of human CTLA4Ig in a non-human primate model of allogeneic pancreatic islet transplantation. J Immunol. 1997; 159(11): 5187-91. PubMed Abstract

65. Larsen $\mathrm{CP}$, Pearson TC, Adams AB et al: Rational development of LEA29Y (belatacept), a high-affinity variant of CTLA4-Ig with potent immunosuppressive properties. Am J Transplant. 2005; 5(3): 443-53. PubMed Abstract | Publisher Full Text

66. F Vincenti F, Charpentier B, Vanrenterghem Y, et al.: A phase III study of belatacept-based immunosuppression regimens versus cyclosporine in rena transplant recipients (BENEFIT study). Am J Transplant. 2010; 10(3): 535-46. PubMed Abstract | Publisher Full Text | F1000 Recommendation

67. Vincenti F, Dritselis A, Kirkpatrick P: Belatacept. Nat Rev Drug Discov. 2011; 10: 655-6.

PubMed Abstract | Publisher Full Text

68. Pescovitz MD: Rituximab, an anti-cd20 monoclonal antibody: history and mechanism of action. Am J Transplant. 2006; 6(5 Pt 1): 859-66. PubMed Abstract | Publisher Full Text

69. Reff ME, Carner K, Chambers KS, et al:: Depletion of B cells in vivo by a chimeric mouse human monoclonal antibody to CD20. Blood. 1994; 83(2): $435-45$.

PubMed Abstract

70. Jiang XR, Song A, Bergelson S, et al:: Advances in the assessment and control of the effector functions of therapeutic antibodies. Nat Rev Drug Discov. 2011; 10(2): 101-11

PubMed Abstract | Publisher Full Text

71. Nelson AL, Dhimolea E, Reichert JM: Development trends for human monoclonal antibody therapeutics. Nat Rev Drug Discov. 2010; 9(10): monoclona

PubMed Abstract | Publisher Full Text

72. Beck A: Biosimilar, biobetter and next generation therapeutic antibodies. MAbs. 2011; 3(2): 107-10.

PubMed Abstract | Publisher Full Text | Free Full Text

73. Niwa R, Satoh M: The current status and prospects of antibody engineering for therapeutic use: focus on glycoengineering technology. J Pharm Sci. 2015; 104(3): 930-41. PubMed Abstract | Publisher Full Text

74. F Herter S, Birk MC, Klein C, et al:: Glycoengineering of therapeutic antibodies enhances monocyte/macrophage-mediated phagocytosis and cytotoxicity. J Immunol. 2014; 192(5): 2252-60. PubMed Abstract | Publisher Full Text | Free Full Text | F1000 Recommendation

75. F Ferrara C, Grau S, Jäger C, et al:: Unique carbohydrate-carbohydrate interactions are required for high affinity binding between FcgammaRIII and antibodies lacking core fucose. Proc Natl Acad Sci U S A. 2011; 108(31): 12669-74.

PubMed Abstract | Publisher Full Text | Free Full Text | F1000 Recommendation

76. F Goede V, Fischer K, Busch R, et al:: Obinutuzumab plus chlorambucil in patients with CLL and coexisting conditions. N Engl J Med. 2014; 370(12): 1101-10.

PubMed Abstract | Publisher Full Text | F1000 Recommendation 


\section{Open Peer Review}

\section{Current Peer Review Status:}

\section{Editorial Note on the Review Process}

Faculty Reviews are review articles written by the prestigious Members of Faculty Opinions. The articles are commissioned and peer reviewed before publication to ensure that the final, published version is comprehensive and accessible. The reviewers who approved the final version are listed with their names and affiliations.

\section{The reviewers who approved this article are:}

\section{Version 1}

\section{Yusuf Tutar}

Division of Biochemistry, Department of Basic Pharmaceutical Sciences, Faculty of Pharmacy, Cumhuriyet University, Sivas, 58140, Turkey

Competing Interests: No competing interests were disclosed.

\section{Janice Reichert}

The Antibody Society, Framingham, MA, USA

Competing Interests: No competing interests were disclosed.

The benefits of publishing with F1000Research:

- Your article is published within days, with no editorial bias

- You can publish traditional articles, null/negative results, case reports, data notes and more

- The peer review process is transparent and collaborative

- Your article is indexed in PubMed after passing peer review

- Dedicated customer support at every stage

For pre-submission enquiries, contact research@f1000.com 